OPEN ACCESS

Edited by:

Harry Wichers,

Wageningen University and Research,

Netherlands

Reviewed by:

Coen Govers,

Wageningen University and Research,

Netherlands

Ran Wei,

The State University of New Jersey,

United States

*Correspondence:

Marie Bodinier

marie.bodinier@inrae.fr

${ }^{\dagger}$ These authors have contributed equally to this work

Specialty section: This article was submitted to Nutritional Immunology, a section of the journal

Frontiers in Immunology

Received: 15 March 2021 Accepted: 29 April 2021

Published: 24 May 2021

Citation:

Rousseaux A, Brosseau C, Le Gall S, Piloquet H, Barbarot S and Bodinier M (2021) Human Milk Oligosaccharides:

Their Effects on the Host and Their

Potential as Therapeutic Agents.

Front. Immunol. 12:680911.

doi: 10.3389/fimmu.2021.680911

\section{Human Milk Oligosaccharides: Their Effects on the Host and Their Potential as Therapeutic Agents}

\author{
Anaïs Rousseaux ${ }^{1 \dagger}$, Carole Brosseau ${ }^{1 \dagger}$, Sophie Le Gall ${ }^{1,2}$, Hugues Piloquet $^{3}$, \\ Sébastien Barbarot ${ }^{3}$ and Marie Bodinier ${ }^{1 *}$ \\ ${ }^{1}$ INRAE, Biopolyméres Interactions Assemblages, Nantes, France, ${ }^{2}$ INRAE, Bioressources: Imagerie, Biochimie \& Structure, \\ Nantes, France, ${ }^{3}$ Centre Hospitalier Universitaire Nantes, UMR1280 PhAN, Nantes, France
}

Breastmilk is known to be very important for infants because it provides nutrients and immunological compounds. Among these compounds, human milk oligosaccharides (HMOs) represent the third most important component of breastmilk after lipids and lactose. Several experiments demonstrated the beneficial effects of these components on the microbiota, the immune system and epithelial barriers, which are three major biological systems. Indeed, HMOs induce bacterial colonization in the intestinal tract, which is beneficial for health. The gut bacteria can act directly and indirectly on the immune system by stimulating innate immunity and controlling inflammatory reactions and by inducing an adaptive immune response and a tolerogenic environment. In parallel, HMOs directly strengthen the intestinal epithelial barrier, protecting the host against pathogens. Here, we review the molecular mechanisms of HMOs in these different compartments and highlight their potential use as new therapeutic agents, especially in allergy prevention.

Keywords: human milk oligosaccharides (HMO), microbiota, epithelial barrier, immune system, allergy

\section{INTRODUCTION}

Breastmilk plays a crucial role in the development of children and provides initial protection against pathogens (1). Breastmilk is composed of nutritional and immunological compounds such as proteins, lipids, and carbohydrates as well as cytokines, growth factors, antimicrobial compounds (1) and microbes (2). All these compounds are transferred directly from the mother to the infant during breastfeeding. According to the World Health Organization (WHO), breastmilk is the ideal food and provides everything essential for the proper development of the child (1). Indeed, some components of breastmilk are able to modulate the biological systems of the child, especially the microbiota, epithelial barriers and immune system. These modulations have a real impact on the child's health and allow the establishment of functional biological systems essential for adulthood. One of the main components naturally found in breastmilk is oligosaccharides, called human milk oligosaccharides (HMOs). The discovery of HMOs is the result of cooperation between two disciplines: medicine and biology. It started at the end of the 19th century when researchers observed that breastfed infants survived better and had fewer intestinal diseases than formula-fed infants (3) (Figure 1). 


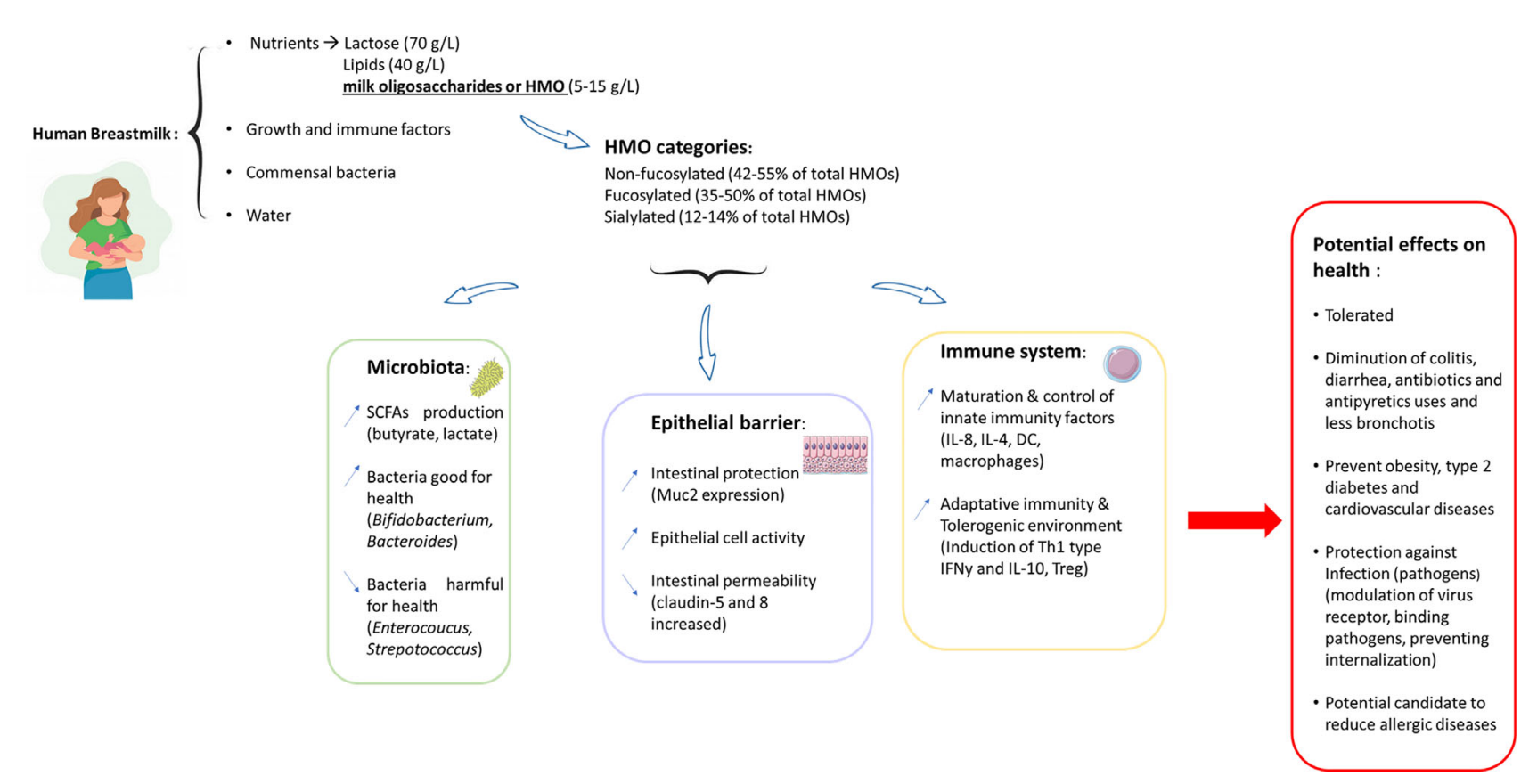

FIGURE 1 | Graphical abstract: beneficial effects of HMOs on human health.

\section{STRUCTURE OF HMOS AND THEIR COMPARTMENTALIZATION IN MOTHERS AND CHILDREN}

HMOs are complex oligosaccharides derived from the elongation of a lactose backbone $(\mathrm{Gal} \beta(1-4) \mathrm{Glc})$ at the nonreducing end galactose $(\mathrm{Gal})$, at the reducing end glucose $(\mathrm{Glc})$ by a fucose residue (linked in $\alpha 1-2 / \alpha 1-3$ ) and/or at the nonreducing end Gal by a sialic acid residue (linked in $\alpha 2-3 / \alpha 2-6$ ) or by disaccharides lacto-N-biose I (linked in $\beta 1-3$ ) or $N$-acetyllactosamine (linked in $\beta 1-3 / 6$ ) (Figure 2) (5). Additional elongation can occur, and more than 150 HMOs have been described to date (5).

HMOs in breast milk are usually classified regarding their -osidic composition as fucosylated neutral HMOs $(35-50 \%$ of total HMOs), nonfucosylated neutral HMOs (42-55\% of total HMOs) and sialylated HMOs (12-14\% of total HMOs) (6).

HMO concentrations in milk are dependent on several factors. Their concentration varies during lactation from 20-25 $\mathrm{g} / \mathrm{L}$ in colostrum to $5-20 \mathrm{~g} / \mathrm{L}$ in mature milk (7). Indeed, 2'fucosyllactose (2'-FL) and lacto-N-fucopentaose (LNFP) are especially present during early lactation, whereas 3'fucosyllactose (3'-FL) increases across the lactation period (8). Conversely, the lacto-N-neotetraose (LNnT) concentration in milk decreases during lactation, including 2'-FL and LNnT (9). Sialylated HMOs are more abundant in colostrum (approximately $1018 \mathrm{mg} / \mathrm{kg}$ of fresh milk or milk from baby food companies), are less concentrated in transitional and mature milk (approximately 696 and $365 \mathrm{mg} / \mathrm{kg}$ of fresh milk or from baby food companies, respectively) and are not found in late lactation milk (10).
The composition of HMOs in human milk is also dependent on genetic factors, including secretor and Lewis blood status of women (Table 1) $(21,22)$. The secretor gene (Se) encodes an $\alpha 1$ 2-fucosyltransferase (FUT2), and the Lewis gene (Le) encodes an $\alpha 1-3 / 4$-fucosyltransferase (FUT3), allowing the fucosylation of HMOs. Fucosyltransferase polymorphisms generated by the individual capacity of women to express these enzymes lead to four genetic expression profiles: $\mathrm{Se}+\mathrm{Le}+$ (Lewis a-b+), Se-Le+ (Lewis $a+b-)$, Se+Le- (Lewis a-b-) and Se-Le- (Lewis a-b-). For example, women without functional FUT2 cannot produce 2'-FL or LNFPI (21). This lack of HMOs may induce consequences for metabolic activities, especially diarrheal diseases, in infants (23). On the other hand, women without functional FUT3 cannot produce HMOs with $\alpha 1,3 / 4$ fucosyl linkages such as 3 '-FL and LNFPII (24). Recently, glucose levels in the blood of the mother were shown to affect the composition of HMOs in breastmilk. Indeed, the presence of sialylated HMOs is associated with a low concentration of fasting plasma glucose and insulin in nonsecretor mothers. In secretor mothers, insulin sensitivity is associated with a high concentration of difucosyllactose and LNFPII (25).

Furthermore, HMOs composition in breastmilk is also dependent on the geographical locations in the world. GomezGallego et al., studied the milk composition from 79 healthy women from Finland, Spain, South Africa, and China (26). They showed that in Chinese sample LNFPIII and 3'-FL are more abundant compared to Finland sample but LNFPI and 2'-FL are more abundant in Finland and Spain samples compared to Chinese and South Africa samples. A higher abundance of 3'-FL is also observed in South Africa sample compared to Finland and Spain samples. 


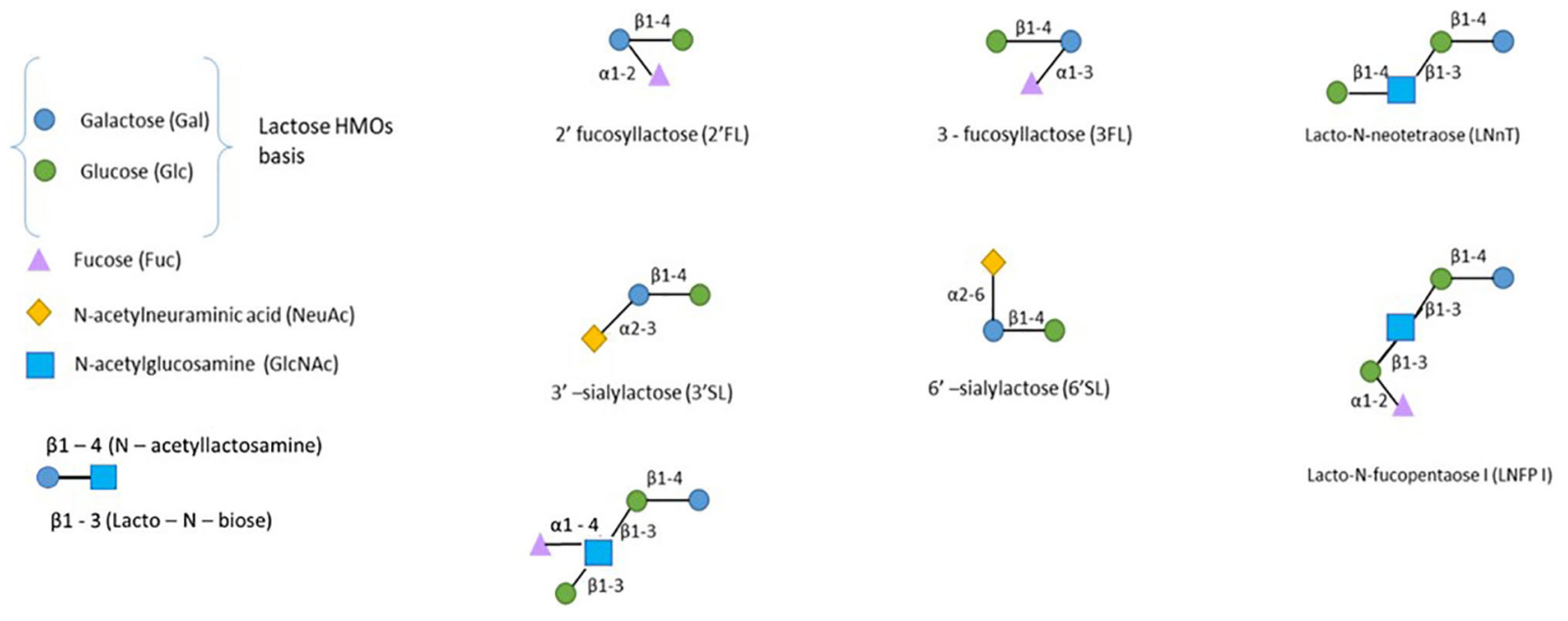

Lacto-N-fucopentaose II (LNFP II)

FIGURE 2 | The structure of human milk oligosaccharides. HMOs can be classified into neutral fucosylated HMOs (2'-FL, 3FL, and LNFPI-II), neutral HMOs (LNnT) and sialylated HMOs (3'SL and 6'SL). Only the most prevalent HMOs are presented here (4).

The vast majority of HMOs reach undigested the large intestine where they provide selective substrates for specific gut bacteria, modulate the immune system, and prevent the epithelial adhesion of intestinal pathogens (27). A small proportion is absorbed intact and excreted in the urine. The presence of intact $\mathrm{HMO}$ in the urine of breast-fed infants was first described in 1996 by Rudloff and colleagues (28), with subsequent clinical studies reporting absorption rates of $1-5 \%$ HMO from the gut intestinal tract to the circulatory system (29). Weather HMOs are absorbed in the upper gastrointestinal tract and/or in the large intestine is unknown. Because it was demonstrated that the small intestine is the main site of nutrient absorption (30), we can postulate that HMOs absorption occurs mainly in the upper gastrointestinal tract but further investigation in vitro need to be performed with representative cell lines of the colon or the small intestine. Experiments using Ussing Chamber Assay, performed on different part of the small intestine or colon to estimate the uptake of the HMOs could be considered.

Interestingly, HMOs concentrations in the child urine or in the circulatory system correlate with the levels in the mother's milk. HMO contribute then to the development and physiological functions of other organs and systemic cell systems. Indeed, while fractions of absorbed HMOs are low, these concentrations were shown to have biological effects in vitro and could explain some of the benefits of human milk (31).

In conclusion, it was shown that HMOs are present in maternal serum during pregnancy (32). HMO concentration and composition in the serum varies according to secretor status and gestational age but also according to geographic or environmental factors (33). 2 '-FL seems to be produced between the end of the first trimester and mid-pregnancy, contributing to an increase in total HMOs in Se+ women. Another study demonstrated that HMOs are also present in cord blood and suggested the placental transfers of HMOs from the maternal bloodstream to the fetal bloodstream (34).

\section{HMOS EFFECTS ON THE GUT EPITHELIAL BARRIER}

The intestinal barrier is constantly renewing itself through the production of epithelial cells at the base of the villi (35). These cells migrate into the intestinal lumen and differentiate throughout their ascent along the villi. Some of these cells will allow the absorption of nutrients (enterocytes), and others will produce mucus (goblet cells) to protect epithelial cells against pathogens present in the lumen (35). The proliferation of epithelial cells must be controlled because overactivation of cell proliferation could induce intestinal cancer (36).

\section{HMOs Effects on Epithelial Cells}

First, Angeloni et al. demonstrated that sialylated HMO fractions (especially 3'SL) induce a modification of the extracellular glycosylation pattern of the Caco-2 cell line (37). This modification was associated with a $50 \%$ reduction in enteropathogenic E. coli in Caco-2 cells treated with 3'-SL compared to untreated cells (Figure 3). Moreover, Chunli Kong et al. demonstrated that 3'-FL increased albumin absorption and the presence of heparan sulfate (HS) and hyaluronic acid (HA) in the glycocalyx of a Caco-2 cell line (38).

In 2008, Kuntz et al. observed that neutral and acidic fractions of HMOs induced cell growth inhibition of small intestinal epithelial cells (HIECs), HT-29 cells and Caco-2 cells in vitro (39). Furthermore, these two fractions of HMOs induced HT-29 and HIEC differentiation but not Caco-2 cell differentiation. 
TABLE 1 | Overview of studies used in this review demonstrating the role of HMOs in host protection (clinical trials).

Study Workforce Intervention Efficiency

Morrow et al. (11) 93 breast-feeding motherinfant Diarrhea was diaenosed by a study Observational clinical pairs from birth to 2 years trial

Marriage et al. (12) Randomized and prospective clinical trial
Infants were exclusively fed either formula ( $n=189$ ) or Human Milk ( $\mathrm{n}=65$ )
Kajzer et al. (13)

Prospectvie, randomized, multicenter, doubleblinded, controlled 3arm tolerance study in full term, singleton infants (birth weight $\geq$ 2490g) enrolled between 0 and 8 days of age

Sprenger et al. (9) An observatory, single center, longitudinal cohort study
Experimental Formula 1 (EF1) did not contain

oligosaccharides $(n=42)$ and

Experimental Formula 2 (EF2) contained $2 \mathrm{~g} / \mathrm{LscFOS}$ and 0.2 ./ L2'FL( $n=46)$. The 2 formula groups were compared with a human milk-fed $(\mathrm{HM})$ reference group ( $n=43$ )

50 mothers, who gave birth to 25 female and 25 male singleton infants
Puccio et al. (14) A Randomized Multicenter Trial
Healthy infants, 0 to 14 days old, were randomized to an intact-protein, cow's milkbased infant formula (control, $n=87$ ) or the same formula physician.

Milk samples obtained 1 to 5 weeks postpartum were analyzed for oligosaccharide content.

Data were analyzed by Poisson regression.

In healthy, singleton infants (birth weight $\geq 2490 \mathrm{~g}$ ).

Formula-fed infants were randomized to 1 of 3 formulas with a caloric density of $64.3 \mathrm{kcal} / \mathrm{dl}$.

Each formula contained galactooligosaccharides, and the 2 experimental formulas contained varying levels $(0.2$ and $1.0 \mathrm{~g} / \mathrm{L})$ of the HMO 2'-fucosyllactose (2'FL). The 3 formula groups were compared with an HM-fed reference group

Infants were exclusively fed formula or human milk from enrolment untli 35 days of age

Data related to intake, stool patterns, anthropometrics and parental questionnaires were collected. The primary outcome was average mean rank stool consistency (MRSC) from Study Day 1 to Visit 3. MRSC was calculated from stool records (1=watery, $2=$ loose/ mushy,3=:soft, 4=formed, 5=hard). Quantitative human milk collection at 30,60 , and 120 days postpartum from 50 mothers, who gave birth to 25 female and 25 male sineleton infants.

Quantification of the 5 representative HMOs: 2'FL, Lacto-N-tetraose (LNT), Lacto-N-neotetraose (LNT), 3'Sialyllactose (3'SL) and 6'Sialyllactose (6'SL). We grouped the milk samples and corresponding infants according to the measured milk 2'FL concentrations at 30 days of lactation, which clustered around low concentrations (95\% Cl of mean 12$42 \mathrm{mg} / \mathrm{L})$ and high concentrations (95\% Cl of mean 1880-2460 mg/L) with the former likely representing Secretor negative mothers. Infant anthropometric measures were recorded at birth, 1, 2 and 4 months of age. Relations among the quantified $\mathrm{HMOs}$ and the relation of the high and low 2'FL HMOs groups with infant growth parameters were investigated via linear mixed models All infants received standard follow-up formual without HMOs from 6 to 12 months. Primary endpoint was weight gain through 4 months. Secondary endpoints Included additional
Campylobacter diarrhea occurred less often in infants whose mother's milk contained high levels of 2'-FL. Colicivirus diarrhea occurred less often in infants whose mother's milk contained high levels of lacto-N-difucohexaose (LDFH-I).

Growth and 2'-FL uptake were similar to those of HM-fed infants

2'-FL and fructo-oligosaccharides fed from less than eight days of age for approximately one month was well tolerated; stool consistency, anthropometric data, and frequency of feedings with spitting up/vomiting and was similar to that of infants given formula without oligosaccharides or to infants breastfed

2'-FL doesn't influence height, weight, BMl, and head circumference of the infants who consumed breast milk with low or high FUT2 associated $\mathrm{HMO}$ concentrations and composition
2'-FL and LNnT were well-tolerated and supported age-appropriate growth. Gastrointestinal symptoms (flatulence, spitting up. and vomiting) were similar between the groups. Enfants receiving formula with $2^{\prime}-F L$ and LNnT had significantly softer stools, and infants born by caesarian section also had a lower incidence of colic at four 
TABLE 1 | Continued

\begin{tabular}{l} 
Study \\
\hline Kuhn et al. (15) \\
Early weaning trial in \\
958 HIV-infected \\
women
\end{tabular}

Seppo et al, (16)

A prospective birth cohort designed to assess immunologic factors in human milk development of CMA within the first18 months of life and oversampled for newborns at high risk for food allergies

Sprenger et al. (17) Randomized controlled trial

Miliku et al., (18) CHLID cohort

Nowak-Wegrzyn et al., (19) Randomized controlled trial
Non-CMA infant $\mathrm{n}=41$ CMA infant $=39$

\section{FUT2-dependent} oligosaccharides in breast milk samples of mothers $(n=266)$ from the placebo group of a randomized placebo-controlled trial of prebiotics and probiotic as preventive against allereic disease in infants with high allergy risk (trial registry number: NCT00298337). 421 mother-infant dyads from the Canadian Healthy Infant Longitudinal Development (CHILD) cohort

Of the 82 children with CMPA that were screened, 67 (intention-to-treat [ITT] cohortmean age $24.5 \pm 13.6$ months; range 2-57; 45 [67.2\%] male ) were randomized to receive either the Test or the Control formula during the first DBPCFC

\section{Intervention}

anthropometric measures, gastrointestinal tolerance, behavioral patterns. and morbidity through age 12 months

Breast-milk samples collected at $1 \mathrm{mo}$ postpartum were analyzed for $\mathrm{HMO}$ content. Samples were selected to include mothers of al HIV-infected children detected by 6 wk of age, of whom 63 died at <2 y of age; mothers of all HEU children who died at $<2$ y of age $(n=66)$; and a random sample of 77 HEU survivors. Associations before and after weaning in HIV-infected and HEU infants separately were investigated by using Cox models

The earilest available milk sample was assessed from each mother; at median 1.0 months in 41 mothers of non-CMA (cow's milk allergy) infants and at median 1.4 in 39 mothers of CMA infants.

CMA was verified by oral food challenges at median 6 months of age. $\mathrm{HMO}$ composition was measured by HPLC after 2aminobenzamide labeling. Raffinose was added to milk samples as internal standard to allow for absolute quantification. Using logistic regression models, we studied associations between FUT2dependent breast milk oligosaccharides and incidence of allergic disease at 2 and 5 years of age.

Associations of 19 individual HMOs and overall $\mathrm{HMO}$ profiles with food sensitization at 1 year of age using Projection on Latent StructuresDiscriminant Analysis (PLS-DA) A whey-based EHF (Test formula) containing 2'fucosyl-lactose (2'FL) and lacto- $\mathrm{N}$-neotetraose ( $\mathrm{LNnT}$ ) was assessed for clinical hypoallergenicity and safety.

The Control formula was a currently marketed EHF without HMO. Children with CMPA (cow's milk protein allergy), aged 2 months to 4 years, were assessed by doubleblind, placebo-controlled food challenges (DBPCFC) to both formulas, in randomized order. If both DBPCFC were negative, subjects participated in a one-week, open food challenge (OFC) with the Test

\section{Efficiency}

months of age. Infants fed the formula with 2 '-FL and LNnT compared to Infants fed the formula without HMOs had significantly fewer parental reports of bronchitis, reduced incidence of lower respiratory tract infections, reduced use of antipyretics and reduced use of antibiotics

2'-FL reduce mortality in HIV non infected infant from HIV infected mother

Enfant fed with breatsmilk with high level of LNPIII are protected against cow's milk allergy compared tp children fed with breatsmilk containing low level of LNPIII.

Infants born by C-section and having a high hereditary risk for allergies might have a lower risk to manifest lgE-associated eczema at 2 years, but not at 5 years of age, when fed breast milk with FUT2 -dependent milk oligosaccharides.

HMOs composition in the human milk is associated with food sensitization in the first year of life could lead to a food allergy later

Hydrolyzed formula supplemented with 2'-FL and LNnT met the clinical hypoalleragenicity criteria and can be recommended for the management of cow's milk protein allergy in infants and young children 
TABLE 1 | Continued

\begin{tabular}{|c|c|c|c|}
\hline Study & Workforce & Intervention & Efficiency \\
\hline $\begin{array}{l}\text { Lodge et al., (20) } \\
\text { the Melbourne Atopy } \\
\text { Cohort Study }\end{array}$ & $\begin{array}{l}\text { Colostrum and early lactation } \\
\text { milk samples were collected } \\
\text { from } 285 \text { mothers enrolled in a } \\
\text { high-allergy-risk birth cohort, } \\
\text { the Melbourne Atopy Cohort } \\
\text { Study }\end{array}$ & $\begin{array}{l}\text { formula. } \\
\text { Symptoms and adverse events were } \\
\text { recorded. Hypoallergenicity was } \\
\text { accepted if at least } 90 \% \text { (with } 95 \% \\
\text { confidence intervals) of subjects } \\
\text { tolerated the Test formula. } \\
\text { Nineteen HMOs were measured. } \\
\text { Profiles/patterns of maternal HMOs } \\
\text { were determined using LCA. } \\
\text { Details of allergic disease outcomes } \\
\text { including sensitization, wheeze, } \\
\text { asthma, and eczema were collected at } \\
\text { multiple follow-ups up to age } 18 \text { years. } \\
\text { Adjusted logistic regression analyses } \\
\text { and generalized estimating equations } \\
\text { were used to determine the relationship } \\
\text { between HMO profiles and allergy }\end{array}$ & $\begin{array}{l}\text { Compared with children exposed to the neutral Lewis HMO profile, } \\
\text { exposure to acidic Lewis HMOs was associated with a higher risk of } \\
\text { allergic disease and asthma over childhood, whereas exposure to the } \\
\text { acidic-predominant profile was associated with a reduced risk of food } \\
\text { sensitization }\end{array}$ \\
\hline
\end{tabular}

Finally, only neutral HMOs induced HT-29 and HIEC apoptosis characterized by caspase 3 cleavage but not Caco- 2 cells supporting the hypothesis of differentiation-associated processes. They concluded that HMO are able to induce growth inhibition in intestinal cells through two different mechanisms, by suppressing cell cycle progression through induction of differentiation and/or by influencing apoptosis. By inducing the differentiation of intestinal cells in vitro, HMOs may influence the maturation of the intestinal barrier (Figure 3). Indeed, Holscher et al. determined that neutral HMOs induced the differentiation of HT-29 cells in villus enterocyte-like cells, promoting digestive capacities of the epithelial barrier (40). Finally, Perdijk and colleagues confirmed that sialylated HMOs influence intestinal cell homeostasis in vitro, highlighting the beneficial effect of HMOs on epithelial cells (41).

In conclusion, some studies demonstrated that HMOs are able to modify the extracellular glycosylation of epithelial cells limiting the adhesion of some pathogens and enhancing albumin absorption. A couple of another studies agree on the effects of HMO on the modulation of the cell cycle preventing cell growth and inducing cell differentiation in villus enterocyte-like cells leading to a potential better absorption of nutrients. As the development and maturation of digestive and absorptive processes depend on differentiation, studies show that HMOs are effective at influencing various stages in gastrointestinal development.

\section{HMOs Effects on the Function of Intestinal Barrier}

HMOs can also protect the intestine by inducing the production of mucin (Figure 3). Mucin is the main protein that composes intestinal mucus and protects against intestinal infection (42). Indeed, $\mathrm{Wu}$ et al. demonstrated that exposure of human intestinal epithelial cells and intestinal organoids to HMOs induced expression of Muc2, a chaperone protein, that then activated disulfide isomerase (PDI) in vitro (43). They also showed an increase in Muc2 expression and a decrease in intestinal permeability in an HMO-supplemented murine model.
Suligoj et al. demonstrated in their study that 2'-FL alone or 2'-FL mixed with LNnT induced the expression of the claudin-8 gene in Caco-2 cell monolayers and that the fermentation of 2'FL induced the expression of claudin-5 in gut-on-chips from human organoids derived from proximal, transverse, and distal colon biopsies (44). Claudin proteins play a crucial role in tight junctions between two epithelial cells, blocking the passage of molecules in the paracellular pathway and thus decreasing the permeability of the gut (45) (Figure 3).HMOs incubated with B. longum infantis increased mRNA transcription of ZO- 1 and the junctional adhesion molecule (JAM-A) in Caco-2 cells and HT-29 cells (46). Furthermore, the authors demonstrated that HMOs prevent the internalization of occludins inside Caco-2 and HT-29 cell lines (46). However, Sua Kim et al. demonstrated that ZO-1 and occludins are necessary to maintain transepithelial electrical resistance and thus to preserve the function of the proximal tubular epithelium (47). ZO-1 (and ZO-2) are involved in the regulation of tight junction assembly, and JAM-A proteins regulate the structural organization of tight junctions, which is essential for the impermeability of the epithelial barrier (48).

In conclusion, these studies highlight the efficiency of HMOs to protect and strengthen the impermeability of intestinal barrier by modulating mRNA transcription and protein expression of several key molecules such as ZO-1, muc2 and claudin.

\section{HMOs Effects on the Activity of Epithelial Cells}

HMOs can affect the protein expression of epithelial cells because a small portion of HMOs are absorbed by intestinal cells (Figure 3). Acidic oligosaccharides were shown to only pass through intestinal cells via the nonspecific paracellular route, and neutral oligosaccharides were shown to pass through intestinal cells via the paracellular or transcellular route involving the receptor pathway (49). The action of HMOs on gene expression was also demonstrated in vivo, showing that supplementation with sialylated HMOs in rats affects intestinal gene expression and modulates the intestinal glycome (50). Sialylated HMOs reduce the secretion of IL- 
12 in Caco- 2 cells and decrease the gene expression of IL-12, IL-8, and TNF $\alpha$ (51). NF- $\mathrm{kB}$ gene expression and protein translocation were also reduced by HMOs in that study. These effects are mediated by the induction of the nuclear receptor PPAR $\gamma$, leading to the regulation of anti-inflammatory peptidoglycan recognition protein 3 activation. It was also shown in HT-29 and Hep-2 cell lines that 2'-FL induced a decrease of $80 \%$ in C. jejuni invasion, and this decrease was associated with suppression of mucosal proinflammatory cytokine secretion (IL-8, IL-1 $\beta$ and neutrophil chemoattractant macrophage inflammatory protein 2) (52).

One in vitro study revealed that 2'-FL could have promising beneficial effects on allergy signaling pathways by selectively inhibiting IL-8 and CCL20 release by T-84 and HT-29 in response to the antigen-antibody complex in the PPAR $\gamma$ dependent pathway (53) (Figure 3).

In conclusion, all these studies converge to demonstrate that HMOs reduce pro-inflammatory cytokines secretion by epithelial cells.

\section{HMOS PROMOTE THE PROLIFERATION OF SPECIFIC INTESTINAL BACTERIAL STRAINS AND THE SECRETION OF SHORT-CHAIN FATTY ACIDS}

The infant microbiota is essentially transmitted from the mother at parturition and during lactation (54). Microbial ecosystems are essential for the good health of the child and need to be developed quickly after birth and during the first months of life (55). The first body site to be colonized is the intestinal tract (GI) (55) by aerobic bacteria (for example Enterococcus). Oxygen consumption by these bacteria then promotes the colonization of anaerobic bacteria in the colon (for example Bacteroides, Clostridia, and Bifidobacteria). Nevertheless, the microbial system of children is extremely variable in terms of composition and stability before becoming more stable in adulthood (56). HMOs influence the composition of the intestinal tract microbiota by selecting for some bacterial species (56), such as Bifidobacterium and Bacteroides, which indirectly prevents the colonization of other bacterial strains in the infant gut (55). Some in vitro and in vivo studies were conducted to evaluate the effect of HMOs on gut bacteria.

\section{In Vitro Studies}

Zhuo-Teng $\mathrm{Yu}$ et al. revealed that 2'-FL and 3'-FL induced Bifidobacteria and Bacteroides growth in vitro. Conversely, these 2 HMOs do not generate major growth effects in Lactobacillus, Enterococcus, and Streptococcus (57). Additionally, 3'SL and 6'SL induced moderate growth of Bifidobacteria and Bacteroides (57), two commensal bacteria known to be good for human health (5860). Conversely, Enterococcus (61) and Streptococcus (62) are two bacteria that induce human infection. Other in vitro studies were conducted and demonstrated that HMOs are able to decrease the colonization (63) and growth (64) of group B Streptococcus. Moreover, Salli and colleagues demonstrated that 2'-FL induces an increase in members of the phyla Firmicutes and Actinobacteria in vitro (65); Bifidobacteria that are commonly found in the gut belong to the phylum Actinobacteria (66). In this study, 2'-FL

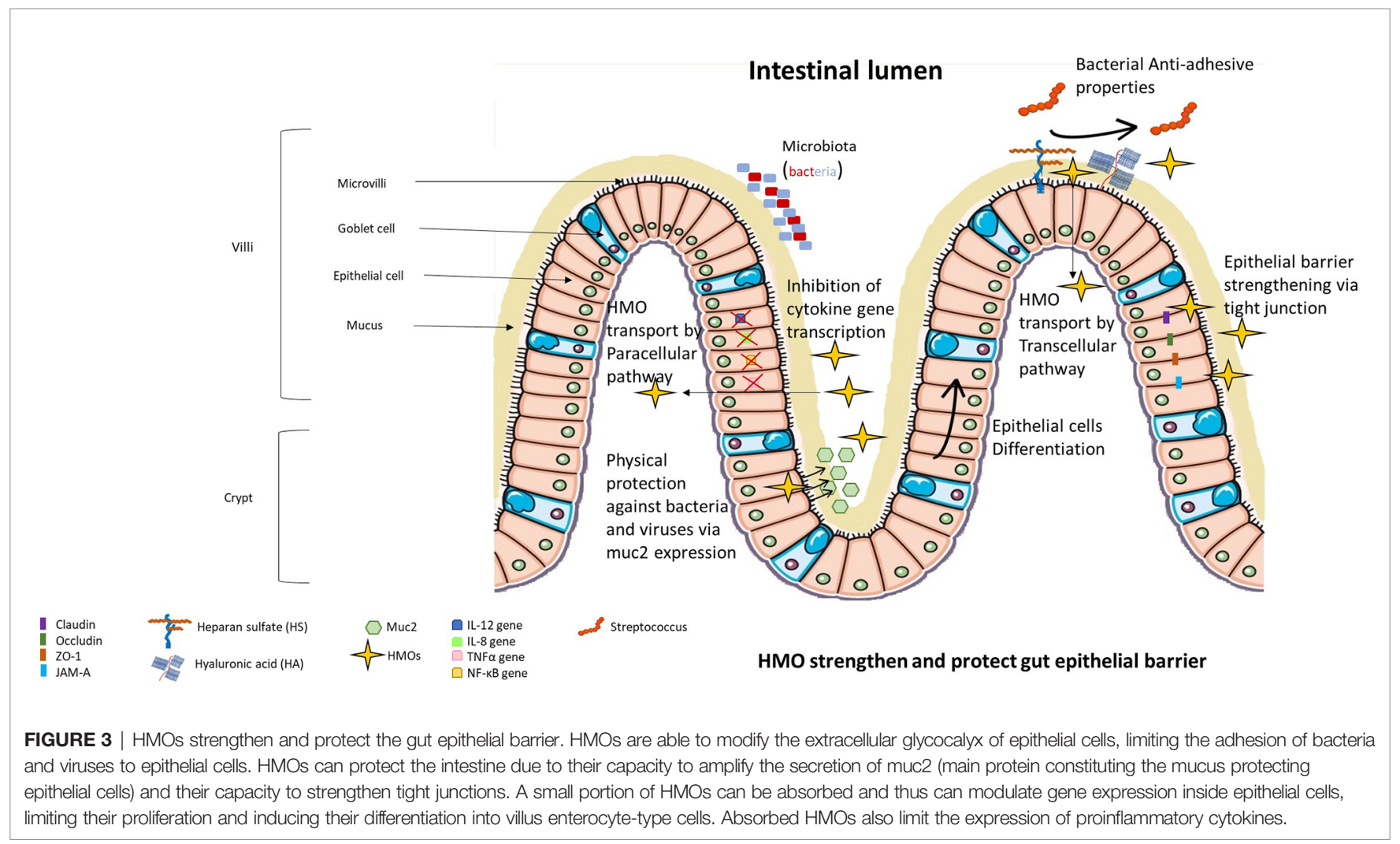


induced a decrease in members of the Proteobacteria phylum that known to cause different diseases (67). Finally, Hoeflinger et al. demonstrated that no Enterobacteriaceae strains grew in the presence of 2'-FL, 6'SL or LNnT (68). In conclusion, all in vitro studies agree that HMOs not only induce the emergence and proliferation of bacteria that benefit health but also decrease the frequency of harmful bacteria.

Interestingly, a very recent study demonstrated that HMOs such as 2'-FL and LNT are hydrolyzed by Akkermansia muciniphila (69). This bacterium is known to colonize the mucus layer of the human intestinal tract and is associated with decreases in obesity, type 2 diabetes, inflammatory bowel disease, and appendicitis (69).

To summarize, these in vitro studies highlight the ability of HMOs to modulate the microbiota inducing on the one hand the growth of bacteria strains benefic for the health and on the other hand the decrease of bacteria strains involved in bacterial infections.

\section{In Vivo Studies}

Two in vivo studies were conducted in newborn pigs supplemented with 2'-FL (10 g/L for 7 days), and both revealed a trend towards an increase in the Lachnospiraceae genus and a decrease in Enterobacteria in the intestine, inducing a nonsignificant diminution of diarrhea in newborn pigs $(70,71)$ (Figure 4).

In clinical trials in humans, HMOs indicated their ability to modulate the microbiota of breastfed preterm infants and breastfed caesarian-born infants, altering the microbiota to be more similar to that of breastfed to term vaginally born infants (increasing Firmicutes and Bifidobacteria and decreasing Enterococcus) (72, 73). Interestingly, Bifidobacteria and Bacteroides were found in the infant fecal microbiota of onemonth-old breastfed children only if their mother secreted 2'-FL and LNFP in milk (74). This finding was correlated with limited infection (75) and protection against obesity (76). HMOs also have an influence on the colon microbiota and are directly fermented by bacteria from the colon (74) (Figure 4). Indeed, the composition of the microbiota is different depending on the HMOs consumed (74). For example, the consumption of all HMOs (nonfucosylated neutral, fucosylated, and sialylated) by one-month-old children induces a higher abundance of Bifidobacteria than the consumption of only one type of $\mathrm{HMO}$ (74). Furthermore, Wang et al. highlighted the correlation between HMO consumption and fecal microbiota composition (77). Indeed, 2'-FL supplementation was positively correlated with the abundance of Bacteroides and negatively correlated with Veillonella, Enterococcus, and Rothia in the feces of infants at 3 months postpartum.

As previously mentioned, the mother secreting status influences the HMO composition in breast milk. Therefore, the presence or absence of HMOs modulates the infant microbiota (78). It was shown that infants fed by secreting mothers had a higher relative abundance of Bifidobacterium strains and Bacteroides strains in feces than infants fed by nonsecretor mothers. Additionally, infants fed by secreting mothers
Intestinal microbiota

HMOs induce growth of bacteria good for health and increase production of SCFAs

\section{Colon microbiota}

HMOs induce growth of bacteria good for health and increase production of SCFAs

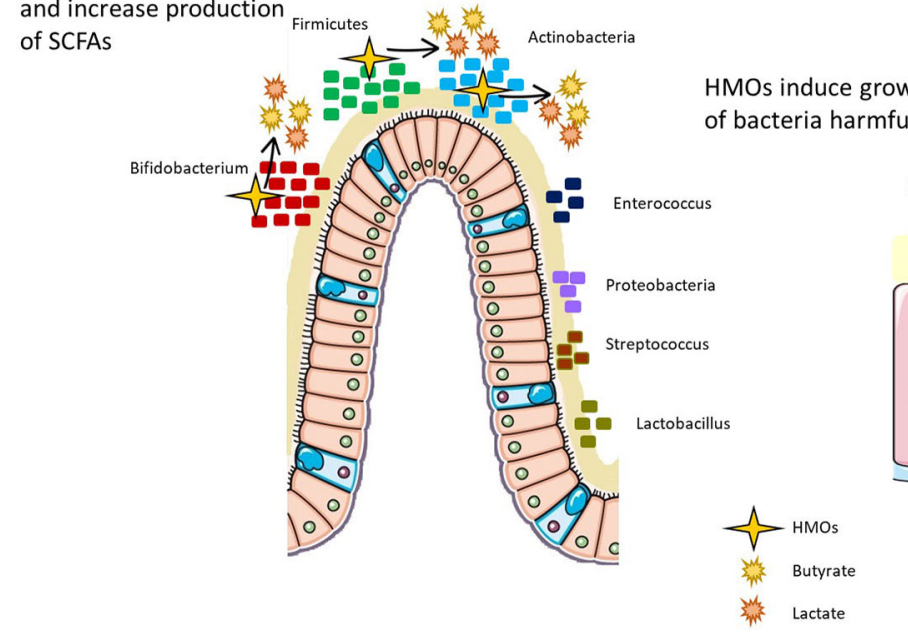

HMOs promote the proliferation of specific intestinal bacterial strains benefic for health and the secretion of short-chain fatty acids

FIGURE 4 | HMOs promote the proliferation of specific intestinal bacterial strains beneficial for health and promote the secretion of short-chain fatty acids. HMOs modulate the intestinal and colon microbiota, inducing the proliferation of Bifidobacterium, Firmicutes, and Actinobacteria in the intestine and Bifidobacterium, Bacteroides, and Lachnospiraceae in the colon. In parallel, HMOs decrease populations of bacteria harmful to health, such as Enterococcus, Proteobacteria, Streptococcus, and Lactobacillus in the intestine and Rothia, Enterococcus, and Clostridia in the colon.
} 
presented fewer Enterobacteria, Clostridia, and Streptococci than infants fed by nonsecretor mothers. Another clinical trial demonstrated that Prevotella was not detected in stools from secretor mothers and their children (79). Similar to previous studies, Bifidobacterium abundance was increased in the stools of children from secretor mothers compared to children from nonsecretor mothers, and this effect was still relevant at 2 to 3 years of age.

Finally, it was shown that the consumption of acidic HMOs protects against microbial structure changes due to stress (80), and neutral HMOs are a selective substrate for some strains of Bifidobacteria (81).

In conclusion, clinical trials demonstrate the importance of the secretor status of mothers for the presence of HMOs in breastmilk and in the composition of the infant microbiota. These clinical trials correlate with the beneficial effects of HMO postnatal consumption and diverse and rich microbiota compositions that are beneficial for health.

\section{Secretion of Short-Chain Fatty Acids}

HMOs can also modify the fermentation activity of the gut microbiota, especially short-chain fatty acid (SCFA) production (Figure 4). SCFAs are an important source of energy for enterocytes and are key signaling molecules for the maintenance of gut health. HMOs can indirectly increase the production of SCFAs, and these augmented levels are mediated by Bifidobacteria species such as B. infantis (82), B. bifidum (83) and $B$. breve (84). Other bacteria able to ferment HMOs such as Bacteroidetes, produce abundant lactate and other SCFAs and consumption of 3'SL and 6'SL by Bifidobacterium and Bacteroides induces greater neuraminidase activity (57). High neuraminidases activity was nevertheless, shown to be involved in human disorders such as neurodegenerative disorders, cancers, and infectious diseases (85). Furthermore, HMOs increase butyrate production in the colon thanks to their fermentation activities (44) (Figure 4).

Human trials and experimental murine models have wildly shown that increasing SCFAs through a high-fiber diet or direct supplementation have beneficial health effects. However, the effects of too high SCFAs concentration on the host has to be investigated, has one study found that higher SCFA concentrations were associated with obesity and hypertension in the adult (86).

\section{EFFECTS OF HMOS ON THE IMMUNE SYSTEM BY DIRECT OR INDIRECT EFFECTS}

In the period directly after birth, the neonate's cellular immune system undergoes rapid development. Multiple immune factors, such as neutrophils, macrophages, monocytes, natural killer (NK) cells, T cells, and dendritic cells (DCs), play a crucial role in fighting against invading pathobionts (87). At birth, an imbalance between Th1/Th17 and Th2 phenotypes is noted in T helper (Th) cell populations. A neonate's immune system is directed more towards the Th2 phenotype, which promotes humoral immunity and confers protection against extracellular pathogens. On the other hand, Th1/Th17 pathways target intracellular pathogens and are less prevalent in developing neonates (Adkins, 2000). The immature immune system is also characterized by overexpression of inflammatory markers and inadequate feedback regulation of immune signaling. It is hypothesized, therefore, that breast-milk oligosaccharides favorably modulate neonatal innate immune responses by controlling the expression of inflammatory markers involved in cell trafficking and by affecting cytokine and chemokine networks that regulate Th1/Th2 lymphocyte balance (88). However, information regarding the role of HMOs and the specificities of their action in inflammation are limited and are largely dependent on findings from in vitro and ex vivo studies.

\section{Direct and Indirect Mechanisms of HMOs on the Immune System}

Because HMOs mediate changes in the composition of the infant microbiota or in the intestinal epithelial cell response, they may indirectly affect the infant immune system. Many in vitro studies suggest that HMOs can also directly modulate immune responses (Figure 5). Indeed, HMOs may act either locally, on cells of mucosa-associated lymphoid tissues, or at a systemic level, as $1-5 \%$ of HMOs are absorbed and reach the circulatory system (89).

\section{Indirect Effects of HMOs on the Immune System via Microbiota and SCFAs}

HMOs can indirectly modulate the immune system by acting on the microbiota, highlighting the important communication between these two biosystems.

HMOs induce the proliferation of Bacteroides fragilis, a bacterial strain that can induce the development of $\mathrm{FOXP}^{+}$regulatory $\mathrm{T}$ cells via a specific "inducible genetic signature" in vitro (90). This was also confirmed in vivo, in which colonization of the mouse intestine by this species increased the production of polysaccharide $\mathrm{A}$, inducing the conversion of $\mathrm{CD}^{+}{ }^{+}$effector $\mathrm{T}$ cells into $\mathrm{FOXP}^{+}$ regulatory $\mathrm{T}$ cells producing the anti-inflammatory cytokine IL-10 (90). Furthermore, lactate produced after HMO fermentation allows the $\mathrm{CD}^{+} \mathrm{T}$ cells to switch to IL- $17^{+} \mathrm{T}$ cell subsets and reduces the cytolytic capacity of $\mathrm{CD}^{+} \mathrm{T}$ cells, modulating the inflammatory immune response (91). In addition, HMO fermentation also produces butyrate, which in turn participates in the regulation of innate and adaptative immune cell generation, trafficking and function (92). Butyrate also inhibits the recruitment and proinflammatory activity of neutrophils, macrophages, dendritic cells and effector T cells. Finally, butyrate is involved in the increase in regulatory $\mathrm{T}$ cell number and activity (92).

In conclusion, indirect effects of HMOs on the immune system tend to promote a tolerogenic environment characterized by an increased regulatory immune balance. These studies conducted in vivo are observational and highlight the correlation between HMOs supplementation and a higher rate and function of regulatory cells. However, the direct link and the proper molecular mechanism have to be deciphered in vitro. 


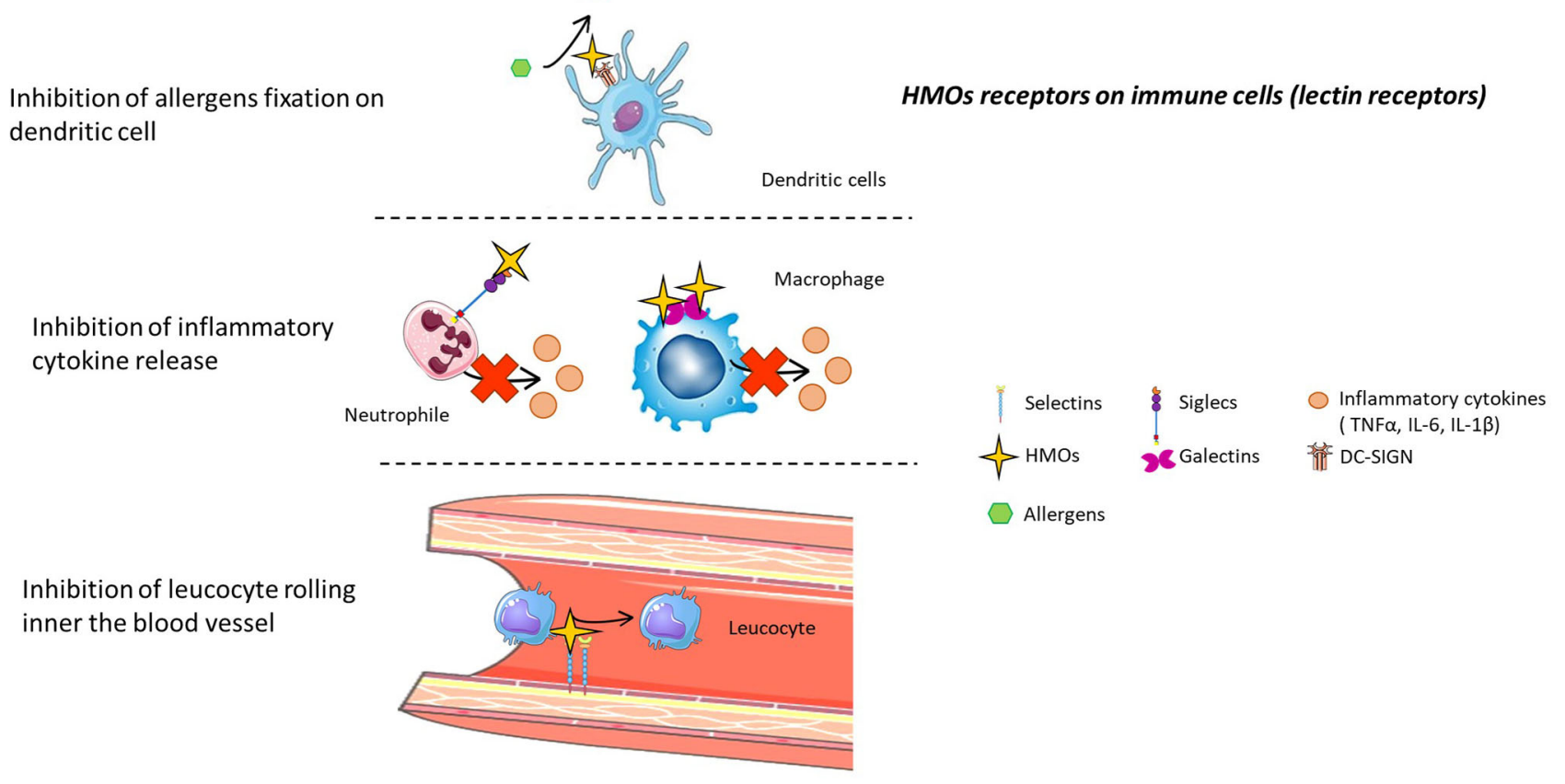

FIGURE 5 | HMO receptors on immune cells (lectin receptors). HMOs can directly interact with the immune system by binding to several receptors present on immune cells. Thus, HMOs can prevent allergic asthma, limit inflammatory cytokine release, and inhibit the rolling of leucocytes inside blood vessels by competing with substrates for these receptors.

\section{Direct Effects of HMOs on the Immune System via Lectin Receptors \\ Galectin Receptors}

HMOs can bind some galectin receptors, such as galectin-1, 2, 3, 7, 8 , and 9 (93). These galectin receptors are expressed by immune cells such as dendritic cells, macrophages, granulocytes and mast cells (94) (Figure 5).

\section{Siglec Receptors}

Sialylated HMOs can bind sialic acid binding immunoglobulinlike lectins (Siglecs), notably Siglecs 5 and 9 (4). These receptors are found on neutrophils, monocytes and dendritic cells, and activation of these receptors after ligand binding leads to the apoptosis of neutrophils, limiting inflammation (95) (Figure 5).

\section{Selectin Receptors}

It was demonstrated that acidic fractions of HMOs in blood inhibit rolling and adhesion of leukocytes (monocyte, lymphocyte and neutrophil cells) to endothelial cells in vitro (96). Sialylated HMOs present epitopes of selectin ligands, sialyl Lewis ( $\mathrm{x}$ ) and sialyl Lewis (a), and thus bind selectin inside the blood vessel, preventing selectin-mediated emigration of leukocytes (97) (Figure 5). Sialylated HMOs can also reduce the formation of platelet-neutrophil complexes (98). Indeed, this complex is mediated by selectin interactions, and thanks to their epitope, sialylated HMOs prevent the interaction between neutrophils and platelets, limiting infectious disease (Figure 5). Lactodifucotetraose (LDFT) also inhibits platelet adhesion to collagen-coated surfaces, preventing their aggregation and activation and thus preventing the release of proinflammatory molecules (99). Finally, it was demonstrated that adjacent neutrophil activation, such as $\beta 2$ integrin expression, was decreased when cells were treated with HMOs (98).

\section{DC-SIGN}

Fucosylated HMOs bind C-type lectin receptors named DC-SIGN receptors (100). DC-SIGN receptors, present on the surface of both macrophages and dendritic cells, are involved in house dust mite allergy because their activation by different major house dust mite allergens induces the secretion of proinflammatory cytokines (101). Thus, HMOs could prevent asthma, allergic rhinitis and atopic dermatitis by binding DC-SIGN and preventing its activation by allergens (Figure 5).

While direct binding of HMOs and receptors was highlighted in various studies in vitro, it would be interesting to inhibit the binding (by siRNA or knock-out for example), to fully determine the impact of the HMOs on the functions of the cells.

\section{HMOs Act on the Immune System, Stimulating Innate and Adaptive Responses HMOs Activate a Controlled Inflammatory Innate Response}

Some HMOs are able to promote the inflammatory response by acting on proinflammatory cytokine secretion (Figure 6). Indeed, a study conducted by Lane et al. (102) demonstrated that HMOs are able to activate the expression of cytokines 


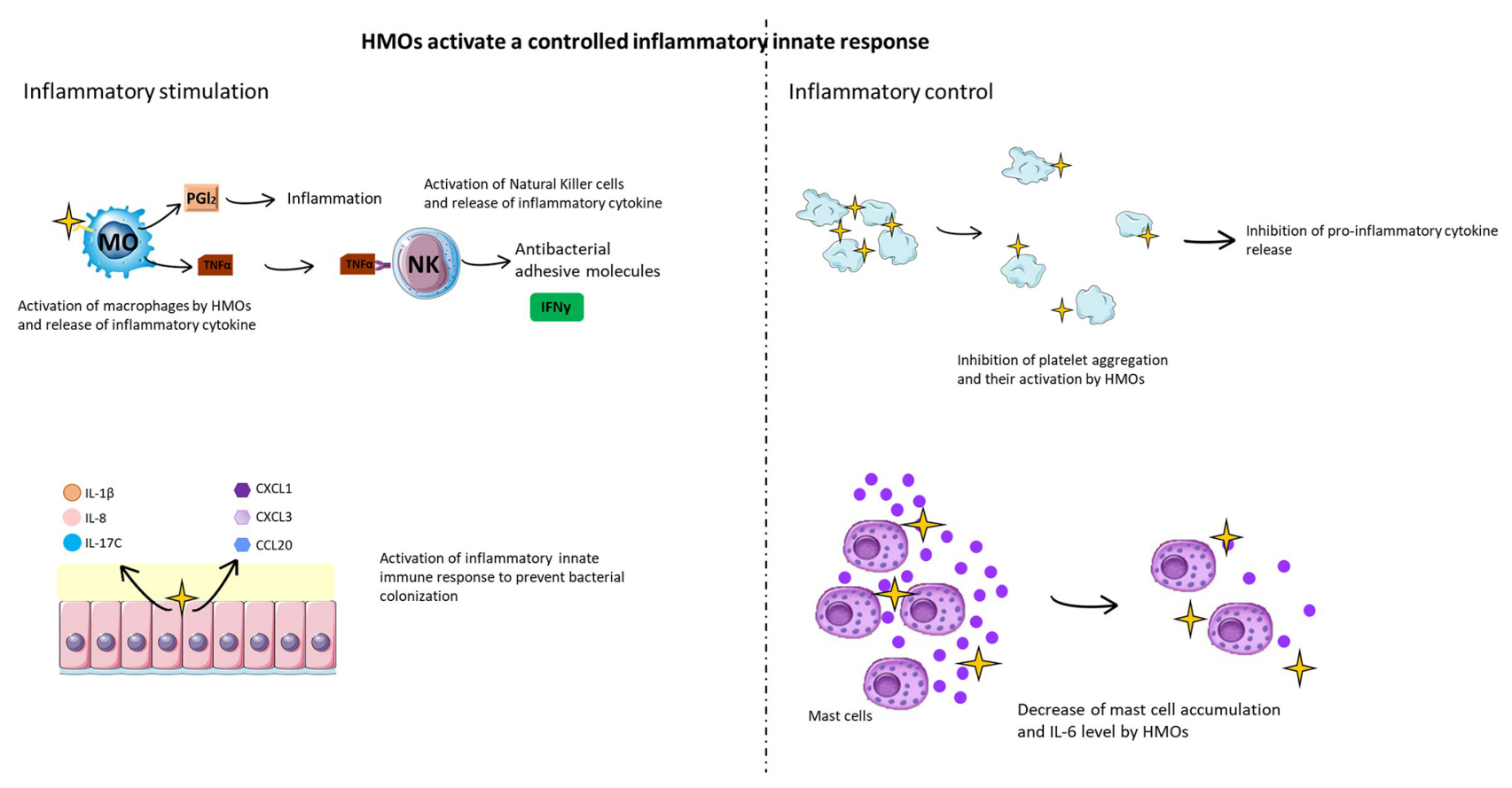

FIGURE 6 | HMOs activate a controlled inflammatory innate immune response. HMOs participate in the inflammatory immune response, stimulating cellular (macrophages, mast cells, natural killer cells, and platelets) and molecular (cytokines and chemokines) actors of the innate response to fight against infection (left figure). In parallel, HMOs limit this inflammatory reaction in a cellular and molecular feedback loop (right figure).

(IL-1 $\beta$, IL-8, IL-17C and platelet factor 4), chemokines (CXCL1, CXCL3, CCL20, CXCL2, CXCL6, CCL5, CX3CL1 and CXCL2) and cell surface receptors (IFN $\gamma R 1$, ICAM-1/2, and IL10R $\alpha$ ) from an HT-29 cell line (colonic epithelial cells) (Figure 6). Usually, the activation of proinflammatory cytokines and chemokines, such as CXCL1, CXCL3, CCL20, IL-8, IL-1 $\beta$, and IL-17C, traduces the establishment of the innate immune response to prevent bacterial colonization (102). LNFPIII and 3'SL have proinflammatory functions mediated by the TLR4 signaling pathway, leading to ERK/MAPK pathway activation (103). LNFPIII is able to mature dendritic cells into a type 2 phenotype, leading to the release of the proinflammatory cytokines IL-4 and IFN $\gamma(104)$. LNFPIII can also activate macrophages in vitro (105), leading to the secretion of prostaglandin 2 and tumor necrosis factor alpha (TNF- $\alpha$ ). These cytokines activate natural killer (NK) cells, inducing an increase in CD69 expression and interferon gamma (IFN $\gamma$ ) production directly at the inflammatory site.

Concerning the effects of HMOs on DC cells, the results are not similar between all studies, probably because of the nature of the HMOs used or the type of DC investigated. Isolated HMOs were found to stimulate semimaturation of human monocytederived DCs, which was associated with elevated levels of antiinflammatory cytokines such as IL-6, IL-10, and IL-20 (106). Ayechu-Marabuzu and colleagues showed that monocytederived DCs exposed to 2'-FL induced IFN $\gamma$ and IL-10 secretion by $\mathrm{CD} 4+\mathrm{T}$ cells and also induced a Th1-driven immune response (107). Another study demonstrated that 3'SL directly stimulates mesenteric lymph node CD11c+ DCs, inducing the production of cytokines implicated in Th1 and
TH17 responses (108). HMOs were also found to reduce LPSinduced production of proinflammatory cytokines such as IL12 p70 and TNF- $\alpha$ by preventing the interaction of LPS and TLR4 (106). Zhang et al. provided further mechanistic insight by demonstrating that a neutral HMO fraction influenced inflammatory cell populations via nuclear factor (NF) $-\kappa B$ and mitogen-activated protein-kinase pathways. Finally, another study performed by Perdijk et al. revealed that HMOs have no effects on the differentiation or maturation of DCs in vitro (109).

However, it is important to mention that this activation of the inflammatory response is controlled. For example, an in vitro study demonstrated that lactodifucotetraose (LDFT) inhibits platelet adhesion to collagen-coated surfaces, preventing their aggregation and activation and thus inhibiting the release of proinflammatory molecules (99) (Figure 6). It was also demonstrated that adjacent neutrophil activation, such as $\beta 2$ integrin expression, was decreased when cells were treated with HMOs (98). Additionally, 2'-FL and 3'FL have anti-inflammatory effects mediated by the TLR4(CD14)/ STAT3/SOCS2 and TLR3 signaling pathways, respectively (105). DSLNT also has an anti-inflammatory effect, but the effect of TLR has not yet been determined. Finally, in a rat model of necrotizing enterocolitis infection, supplementation with the sialylated HMO fraction induced a decrease in mast cell accumulation (Figure 6), DPPi activity and IL-6 levels in ileal tissue compared to nonsupplemented rats (110). It was also shown that mice supplemented with 2'-FL presented a high decrease in the $C$. jejuni infection rate (80\%), a reduction in weight loss, and a decrease in intestinal inflammation and inflammatory signal induction (52). 
Several studies have focused on assessing the immuno modulatory effects of HMO mixtures isolated from human milk. For example, $\mathrm{He}$ et al. assessed the impact of colostral HMOs on intact immature human intestinal mucosa (111). The authors found that colostral HMOs reduced the levels of proinflammatory cytokines (such as interleukin (IL) IL-1 $\beta$, IL-6 and IL-8) while stimulating the expression of cytokines associated with tissue repair and homeostasis.

In conclusion, it seems clear that the effects of HMOs on immune cells depend on the nature of the HMOs. Therefore, elucidating the effects of each HMOs is require to fully understand the mechanistic effects leading to a controlled inflammatory innate response. While the effects of HMOs were well investigated concerning DCs cells, further studies are require on the direct effects of HMOs on other major cellular actors of the innate response such as NK cells or innate lymphoid cells. Finally, in vitro experiments are require to fully understand the molecular mechanism of HMOs on these cells and to make a link between molecular pathways induced and inhibition of inflammatory innate response.

\section{HMOs Activate the Adaptive Immune Response}

HMOs are able to induce a tolerogenic immune response acting on immune cells and molecular factors. Recently, AyechuMuruzabal et al. demonstrated in vitro that 2'-FL was able to induce Th1 type IFN $\gamma$ and regulatory IL-10 secretion of peripheral blood mononuclear cells, whereas Th2 type IL-13 was reduced compared to cells in the absence of 2'-FL (107). He et al. also found that exposure to HMOs elevated the expression of Th1 polarization and shifted the balance of Th1/Th2 cytokines towards that of more mature tissues (111). In addition, 2'-FL activated immature monocyte-derived dendrites, leading to the secretion of IFN $\gamma$ and IL-10 by $\mathrm{CD}^{+} \mathrm{T}$ cells (107) (Figure 7). Another in vitro study investigating the gastrointestinal epithelial transfer of HMOs showed that HMOs can first transfer through a Caco-2 cell monolayer and then significantly suppress Th-2-type cytokine production by Ara h1-specific $\mathrm{CD}^{+} \mathrm{T}$ cells from patients allergic to peanuts (112). Interestingly, supplementation with LNFPIII in a mouse model of schistosome infection induced the proliferation of splenic non-T cells and B220+, CD4-, and CD8- cells secreting IL-10 and prostaglandin 2 (113) (Figure 7). This proliferation leads to a downregulation of the Th2-type immune response, limiting an exacerbated inflammatory reaction. Finally, 3'SL also induces the production of cytokines secreted by Th1 and Th17 cells by direct stimulation of mesenteric lymph node CD11c ${ }^{+}$dendritic cells (108) (Figure 7).

Furthermore, the regulation of inflammation by 2'-FL was also demonstrated in vivo and was characterized by an increase in $\mathrm{IL}-10^{+} \mathrm{CD} 4^{+} \mathrm{CD} 25^{+}$regulatory $\mathrm{T}$ cells from Peyer's patches (Figure 7). Xia et al. demonstrated in vivo that mice supplemented with 2'-FL had increased expression and activity of the CD27 marker on splenic B cells compared with control mice, highlighting the maturation of B cells (114) (Figure 7). They also observed the proliferation of proinflammatory CD4+ CD8+ splenic $\mathrm{T}$ cells with a higher concentration of IFN $\gamma$ in supplemented mice than in control mice (114) (Figure 7). Activation of inflammation by HMOs may appear at an early stage of neonate development, as demonstrated by Eiwegger and colleagues. Interestingly, they showed that acidic HMOs increased the expression of IFN $\gamma$ by $\mathrm{CD}^{+} \mathrm{CD}^{+}$and $\mathrm{CD}^{+} \mathrm{CD} 8^{+}$cord blood $\mathrm{T}$ cells and IL-13 expression by $\mathrm{CD}^{+} \mathrm{CD}^{+}$cord blood $\mathrm{T}$ cells (115). Furthermore, Eiwegger et al. demonstrated that the acidic fraction of HMOs increased $\mathrm{CD} 25$ expression on $\mathrm{CD}^{+} \mathrm{CD}^{+}$cells characteristic of activated regulatory $\mathrm{T}$ cells (115).

One study conducted by Sotgiu et al. revealed that the presence of 2'-FL and LNFPI decreased the LPS-activated mononuclear cell proliferation obtained from multiple sclerosis and healthy patients (116). These 2 HMOs reduced the production of IL-12 and IFN $\gamma$ more significantly in multiple sclerosis patients than in healthy patients. Conversely, IL-10 was increased in both patients. An important clinical trial conducted by Goehring et al. demonstrated that breastfed and formula-fed children with 2'-FL had a similar low concentration of proinflammatory cytokines (IL-1r $\alpha$, IL- $1 \alpha$, IL-1 $\beta$, IL-6, and $\mathrm{TNF} \alpha$ ) compared to children that were not breastfed or supplemented with HMOs at 4 months of age (117).

In conclusion, HMOs are able to induce a tolerogenic immune response acting on immune cells and molecular factors from the adaptive immune pathway. Indeed, HMOs exposure induce a shift of the balance Th1/Th2 towards a Th1 polarization. Effects of some HMOs on T cell and DC cytokine secretion were also described and one study demonstrated that 2'-FL in vivo, increase regulatory $\mathrm{T}$ cells. Effects of HMOs on other major actors of the adaptive immune response need to be more investigated such has CD8 T cells and B cells. The modulation of the regulatory $\mathrm{B}$ cells were not investigated yet. Finally, studies are only observational and the molecular mechanism of HMOs leading to the regulation of the adaptive immune pathway (cell rate, cytokine secretion, cells interaction) still have to be deciphered.

Thus, because HMOs participate in the establishment of controlled inflammatory innate immunity and adaptative immunity and a tolerogenic environment, they could protect children from infections and allergic and autoimmune diseases.

\section{HMOS AS A NEW POTENTIAL THERAPEUTIC AGENT}

Because HMOs present many beneficial effects proven in vitro and in vivo, several studies have been conducted to confirm these beneficial effects against infections and inflammatory diseases. Therapeutic strategies used in clinical trials targeted different windows of opportunity of HMO supplementation to mediate the beneficial effects, such as the early life period, especially for babies in terms of milk formula.

\section{HMOs Tolerance and Health Effect}

It was first necessary to confirm that HMOs were well tolerated and had no side effects (118) (Table 1).

Several studies conducted on newborns fed HMOsupplemented formulas demonstrated digestive tolerance of 


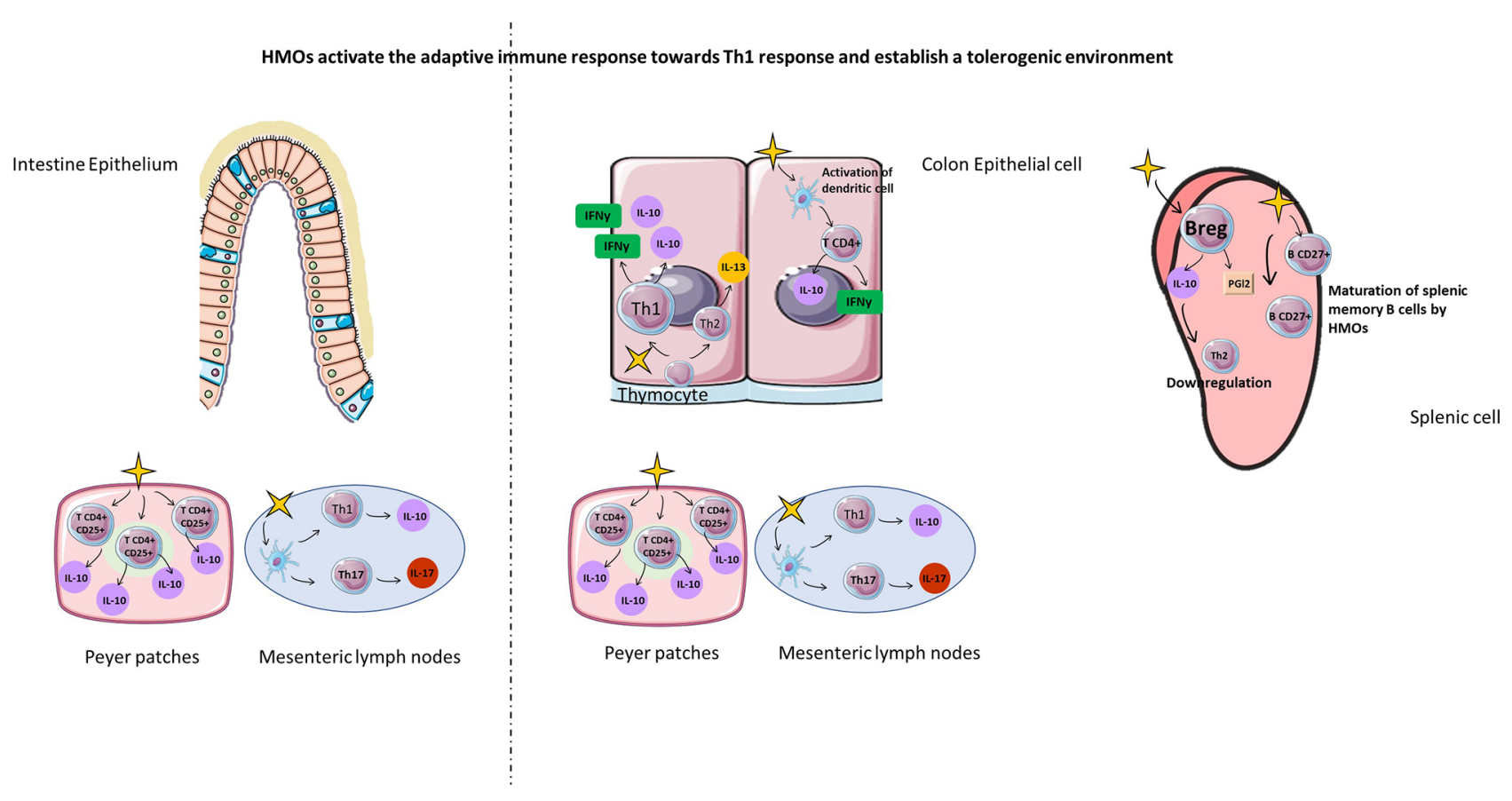

FIGURE 7 | HMOs activate the adaptive immune response towards the Th1 response and establish a tolerogenic environment. HMOs can also act on cellular actors in the adaptative immune (Th1, TH17, TCD4+, Treg, Breg, memory B cells) response in order to fight against infectious diseases with a downregulation of Th2 immune response in the intestine and in the spleen. Furthermore, HMOs are able to introduce a tolerogenic environment with stimulation of Treg and Breg cells.

HMOs and identical child growth (weight, length, and head circumference) compared to breastfed infants $(12-14,117)$ (Table 1). HMOs induce better sleep and a less important pathogens colonization leading to less colic and more Bifidobacterium present in the colon (14). Sprenger et al. (9) demonstrated that children breastfed for 4 months by secreting mothers (with a secretion of 2'-FL) had no difference in weight, size, or body mass index compared to breastfed children from nonsecretor mothers (Table 1). No difference in cranial box circumference was described (119). Finally, it was also shown in pigs that supplementation with 2'-FL improved cognitive performance and influenced brain development (120). All these studies highlight that HMOs do not induce side effects on newborns breastfed by secretor mother or fed with a HMOssupplemented formula. Nevertheless, it would be interesting to follow these children up to a certain age to see if differences appear in the long term or not.

\section{HMOs Effects on Babies' Ailments, Infections and Non-Communicable Diseases}

Because HMOs do not present side effects, they were tested to determine whether they induce a reduction in babies' ailments. Supplemented formula-fed infants who were cesarean born had softer stools and a lower incidence of colic at 4 months of life than nonsupplemented children (14) (Table 1). They had a shorter period of bronchitis at 4, 6, and 12 months, fewer respiratory tract infections and a reduction in antibiotic and antipyretic uses compared to nonsupplemented children (14). It would have been interesting in this study to compare the results obtained in the supplemented formula-fed group with babies fed by secretor mothers to compare the effects of natural HMOs intake versus supplemented formula intake. HMOs are also associated with a reduction in diarrhea induced by Campylobacter during the first 2 years of life of children fed breast milk with a high concentration of 2'-FL compared to those fed with a low level of 2'-FL in the milk highlighting also the importance of the concentration of HMOs in the breast milk (11) (Table 1). In parallel, an important study revealed a decrease in mortality in noninfected children born to HIV-infected mothers due to HMOs in breast milk compared to noninfected children who were not breastfed (11).

Several studies highlighted the protective effects of HMOs against infections. HMOs act as soluble receptors of bacteria or modulate target cells, inhibiting the pathogen-host cell interaction. Indeed, Angeloni et al. demonstrated that 3'SL exposure induces a change in the glycocalyx composition of Caco- 2 cells (37). The expression of $\alpha 2-3$ - and $\alpha 2-6$-linked sialic acid residues was downregulated on the cell surface, leading to a decrease in pathogen receptors on the host cell surface and thus a decrease in bacterial binding. A decrease in virus binding to DLD1 intestinal cells by HMOs was also highlighted (121). Interestingly, this particular effect of HMOs is not limited to intestinal cells. Indeed, Andersson et al. demonstrated that human milk inhibits the attachment of bacteria and viruses on pharyngeal and buccal epithelial cells (122). It was demonstrated 
that the anti-adhesive effect was due to the low molecular weight fraction of human milk, particularly to the oligosaccharides present in this fraction.

Furthermore, HMOs act as antimicrobial agents due to their ability to bind pathogens such as Streptococcus strains directly in the gut (123). In an in vitro study conducted by Weichert et al., the use of X-ray crystallography demonstrated that 2'-FL and 3'FL are able to bind norovirus, linking in the HGBA pocket of the virus, and inhibiting its cytotoxic activity (124). They also demonstrated that HMOs can be direct substrates for pathogens, preventing infection of host cells. Finally, Lin et al. highlighted that sialic acid HMOs protect epithelial cells by preventing the internalization of Escherichia coli in UPEC cells in vitro, inhibiting the infection of the cells (125).

Finally, the anti-adhesive properties of HMOs also applied to some parasitic protozoa. For example, Entamoeba histolytica, (a protozoa that destroys the epithelium of the large intestine and can occur in the liver, lungs or spleen) requires for the infection to attach to the host's colon mucosa. Parasites that cannot attach are excreted in faeces and do not cause disease. It was shown that some HMOs significantly reduce the binding and cytotoxicity of $E$. histolytica during in vivo assays (118). This may explain why breastfed infants are less likely to be infected with $E$. histolytica or other protozoa than formula-fed infants. To summarize, HMOs can prevent infection by 1) modulating virus receptor expression on the surface of the cell, 2) directly binding pathogens inhibiting their adhesion, and 3) preventing internalization through the gut.

Finally, it was shown in animal models that HMOs had protective effects on several non-communicable diseases. 3'SL supplementation is able to prevent the development of obesity in mice and to prevent type 2 diabetes and cardiovascular diseases (126). In the same way, HMOs in breastmilk seem to protect children against obesity until 4 years of age compared to children who were never breastfed (119).

\section{HMOs Are a Potential Candidate to Reduce Allergic Diseases}

Allergies are a major health issue in developed countries, and there is currently no effective therapeutic strategy to cope with allergies. Allergy pathologies are associated with a breakdown of immune tolerance (127), microbiota dysbiosis (128) and an increase in epithelial permeability (129). They may be observed within the first month of life, suggesting the possibility of early childhood preprogramming these biological systems and possibly reducing the risk of allergy development. Due to their beneficial effects on the microbiota, gut epithelial barrier and immune system, HMOs have been tested to treat or prevent allergic diseases. Today, only some preclinical and clinical studies have been conducted in this context.

\section{Preclinical Studies Using HMOs as a Therapeutic Strategy for Allergies}

In a mouse model of food allergies, HMOs were shown to be good candidates to treat or prevent allergic symptoms. Indeed, allergic mice supplemented with 2'-FL had a decrease in allergic symptoms such as diarrhea and hypothermia and a suppression of protease 1 secretion from mast cells mediated by antigen compared to non-supplemented allergic mice (130). The authors also demonstrated a decrease in intestinal mast cell frequency and an increase in $\mathrm{CD} 4{ }^{+} \mathrm{CD} 25^{+} \mathrm{IL} 10^{+}$regulatory $\mathrm{T}$ cells in mesenteric lymph nodes and Peyer's patches. Furthermore, they observed a reduction in the passive response to skin anaphylaxis. Recently, Liu et al., working on a $\beta$-lactoglobulininduced milk allergic mouse model, demonstrated that supplementation with 2'-FL for 4 weeks decreased IgE and $\beta$ lactoglobulin-specific IgE in the serum and increased the levels of the anti-inflammatory cytokines IL-10, TGF- $\beta$, and IFN $\gamma$ compared to allergic mice untreated with 2'-FL, thus preventing allergy development (131).

These encouraging data from preclinical models need to be confirmed by other studies in other allergic contexts, such as asthma or atopic dermatitis, and the mechanistic effects of HMOs must be deciphered.

\section{Clinical Studies Evaluate the Interest of HMOs for Allergies}

Most human studies have correlated the presence of HMOs in breastmilk and the development of allergies in infants, but the results are controversial.

On the one hand, Seppo et al. demonstrated that a high level of LNFPIII in breastmilk protected infants against cow's milk allergy compared to children fed breastmilk containing a low level of LNFPIII (16). On the other hand, Miliku et al. showed that HMO composition in human milk is associated with food sensitization in the first year of life, which can later lead to food allergies (18). Lodge et al. demonstrated that compared with children exposed to the neutral Lewis HMO profile, exposure to acidic Lewis HMOs was associated with a higher risk of allergic disease and asthma during childhood, whereas exposure to the acidic-predominant profile was associated with a reduced risk of food sensitization (20). Finally, the observational clinical trial conducted by Sprenger et al. (132) revealed that infants born by cesarean section and having a high hereditary risk for allergies might have a lower risk of manifesting IgE-associated eczema at 2 years, but not at 5 years of age, when fed breast milk with FUT2-dependent milk oligosaccharides. Further studies with larger cohorts and especially randomized controlled intervention trials are required to build on these preliminary observations.

In an interventional study, Nowak-Wegrzyn et al. attempted to determine whether an extensively hydrolyzed formula supplemented with two HMOs was tolerated by infants allergic to cow's milk (19). They demonstrated that the whey-based extensively hydrolyzed formula supplemented with 2'-FL and LNnT met the clinical hypoallergenic criteria and could be recommended for the management of cow's milk protein allergy in infants and young children.

These different results obtained in clinical trials are contradictory because the studies were conducted in different ways (time of supplementation, concentration, type of HMOs), complicating the understanding of HMO effects on allergic disease. New strategies could be explored to clarify the HMO effect. 


\section{CONCLUSION}

HMO composition (presence/absence of neutral, acidic, and sialylated HMOs) and concentration in breastmilk depend on several factors, such as their different ramification and the stage of lactation. Another important factor is the mother secretor status. If she is Lewis $(+)$ and secretor $(+)$, all HMOs will be secreted, in particular 2'-FL and LNFPIII, which have protective effects on infant and adult health. 2'-FL and LNFPIII modulate the intestinal and fecal microbiota to establish beneficial bacterial colonization, limiting pathogenic bacterial infection and diseases. They are also able to directly bind to pathogens in the gut and to influence intestinal epithelial cells, inducing protection and reinforcement of the epithelial barrier. HMOs directly and indirectly activate the immune system, first activating an inflammatory reaction to prime the organism against infection and, second, activating a tolerogenic environment. Interestingly, HMOs molecular mechanism on the immune system, the epithelial barrier and gut microbiota seems to be very similar and can be compared to exogenous prebiotics such as galacto-oligosaccharides or inulin (133).

Due to the benefits of HMOs, they have been tested in several studies as potential treatments for different diseases, such as obesity, diabetes, virus infection (influenza, NEC) and allergies. Because the implementation of major systems occurs very early in life, even in utero, it would also be interesting to consider preventive strategies, by directly supplementing gestational mothers in HMOs. For example, maternal intake of omega-3, polyunsaturated fatty acid, antioxidants, folates, vitamin $\mathrm{D}$ or probiotics is associated with protection against

\section{REFERENCES}

1. Garwolińska D, Namieśnik J, Kot-Wasik A, Hewelt-Belka W. Chemistry of Human Breast Milk-A Comprehensive Review of the Composition and Role of Milk Metabolites in Child Development. J Agric Food Chem (2018) 66(45):11881-96. doi: 10.1021/acs.jafc.8b04031

2. Oikonomou G, Addis MF, Chassard C, Nader-Macias MEF, Grant I, Delbès C, et al. Milk Microbiota: What Are We Exactly Talking About? Front Microbiol (2020) 14:11-60. doi: 10.3389/fmicb.2020.00060/full

3. Kunz C. Historical Aspects of Human Milk Oligosaccharides. Adv Nutr (2012) 3(3):430S-9S. doi: 10.3945/an.111.001776

4. Triantis V, Bode L, van Neerven RJJ. Immunological Effects of Human Milk Oligosaccharides. Front Pediatr (2018) 2:190/full. doi: 10.3389/ fped.2018.00190/full

5. Bode L. The Functional Biology of Human Milk Oligosaccharides. Early Hum Dev (2015) 91(11):619-22. doi: 10.1016/j.earlhumdev.2015.09.001

6. Donovan SM, Comstock SS. Human Milk Oligosaccharides Influence Neonatal Mucosal and Systemic Immunity. Ann Nutr Metab (2016) 69 (Suppl. 2):41-51. doi: 10.1542/peds.2011-1206

7. Gabrielli O, Zampini L, Galeazzi T, Padella L, Santoro L, Peila C, et al. Preterm Milk Oligosaccharides During the First Month of Lactation. Pediatrics (2011) 128(6):e1520-31. doi: 10.1542/peds.2011-1206

8. Smilowitz JT, Lebrilla CB, Mills DA, German JB, Freeman SL. Breast Milk Oligosaccharides: Structure-Function Relationships in the Neonate. Annu Rev Nutr (2014) 34(1):143-69. doi: 10.1146/annurev-nutr-071813-105721

9. Sprenger N, Lee LY, De Castro CA, Steenhout P, Thakkar SK. Longitudinal Change of Selected Human Milk Oligosaccharides and Association to Infants' Growth, an Observatory, Single Center, Longitudinal Cohort Study. PloS One (2017) 12(2):e0171814. doi: 10.1371/journal.pone.0171814. Wiley AS, editor.

10. Martín-Sosa S, Martín M-J, García-Pardo L-A, Hueso P. Sialyloligosaccharides in Human and Bovine Milk and in Infant Formulas: Variations With the allergic outcomes in children (134). In the context of prebiotics, two clinical studies are currently being conducted: SYMBA (Trial Identification Number: ACTRN12615001075572) and PREGRALL (Trial Identification Number: NCT03183440). SYMBA investigates the effects of maternal prebiotic supplementation from 18-20 weeks gestation during pregnancy until 6 months of lactation on the development of infant allergic disease (135). PREGRALL aims to evaluate the effectiveness of gestational prebiotic supplementation (from 20th week of gestation until delivery) on the occurrence of $\mathrm{AD}$ at 1 year of age in at-risk children (136). Because lactation is also a crucial period for the implementation of major systems, HMO supplementation of breastfed babies from non-secretor mother could be considered as preventive strategy for noncommunicable diseases.

Despite a large number of publications showing the beneficial effects of HMOs on the host (such as protection against allergies), some results are quite controversial, especially due to the lack of homogeneity between all these studies in terms of the time of supplementation, concentration and type of HMOs. More experiments need to be performed to affirm the beneficial effect of HMOs on health.

\section{AUTHOR CONTRIBUTIONS}

AR and CB wrote the paper. SLG, HP, SB and MB reviewed the paper. All authors contributed to the article and approved the submitted version.
Progression of Lactation. J Dairy Sci (2003) 86(1):52-9. doi: 10.3168/jds.S00220302(03)73583-8

11. Morrow AL, Ruiz-Palacios GM, Altaye M, Jiang X, Lourdes Guerrero M, Meinzen-Derr JK, et al. Human Milk Oligosaccharides are Associated With Protection Against Diarrhea in Breast-Fed Infants. J Pediatr (2004) 145 (3):297-303. doi: 10.1016/j.jpeds.2004.04.054

12. Marriage BJ, Buck RH, Goehring KC, Oliver JS, Williams JA. Infants Fed a Lower Calorie Formula With 2'Fl Show Growth and 2'FL Uptake Like Breast-Fed Infants. J Pediatr Gastroenterol Nutr (2015) 61(6):649-58. doi 10.1097/MPG.0000000000000889

13. Kajzer J, Oliver J, Marriage BJ. Gastrointestinal Tolerance of Formula Supplemented With Oligosaccharides. FASEB J (2016) 30:671.4-4. doi: 10.1096/fasebj.30.1_supplement.671.4

14. Puccio G, Alliet P, Cajozzo C, Janssens E, Corsello G, Sprenger N, et al Effects of Infant Formula With Human Milk Oligosaccharides on Growth and Morbidity: A Randomized Multicenter Trial. J Pediatr Gastroenterol Nutr (2017) 64(4):624-31. doi: 10.1097/MPG.0000000000001520

15. Kuhn L, Kim HY, Hsiao L, Nissan C, Kankasa C, Mwiya M, et al Oligosaccharide composition of breast milk influences survival of uninfected children born to HIV-infected mothers in Lusaka, Zambia J Nutr (2014) 145(1):66-72. doi: 10.3945/jn.114.199794

16. Seppo AE, Autran CA, Bode L, Järvinen KM. Human Milk Oligosaccharides and Development of Cow's Milk Allergy in Infants. J Allergy Clin Immunol (2017) 139(2):708-711.e5. doi: 10.1016/j.jaci.2016.08.031

17. Sprenger N, Odenwald H, Kaarina Kukkonen A, Kuitunen M, Savilahti E, Kunz C, et al. FUT2-dependent breast milk oligosaccharides and allergy at 2 and 5 years of age in infants with high hereditary allergy risk. Eur J Nutr (2017) 56(3):1293-301. doi: 10.1007/s00394-016-1180-6

18. Miliku K, Robertson B, Sharma AK, Subbarao P, Becker AB, Mandhane PJ, et al. Human Milk Oligosaccharide Profiles and Food Sensitization Among Infants in the CHILD Study. Allergy (2018) 73(10):2070-3. doi: 10.1111/all.13476 
19. Nowak-Wegrzyn A, Czerkies L, Reyes K, Collins B, Heine RG. Confirmed Hypoallergenicity of a Novel Whey-Based Extensively Hydrolyzed Infant Formula Containing Two Human Milk Oligosaccharides. Nutrients (2019) 11(7):1447. doi: 10.3390/nu11071447

20. Lodge CJ, Lowe AJ, Milanzi E, Bowatte G, Abramson MJ, Tsimiklis H, et al. Human Milk Oligosaccharide Profiles and Allergic Disease Up to 18 Years. J Allergy Clin Immunol (2021) 147(3):1041-8. doi: 10.1016/j.jaci.2020.06.027

21. Kunz C, Meyer C, Collado MC, Geiger L, García-Mantrana I, Bertua-Ríos B, et al. Influence of Gestational Age, Secretor, and Lewis Blood Group Status on the Oligosaccharide Content of Human Milk. J Pediatr Gastroenterol Nutr (2017) 64(5):789-98. doi: 10.1097/MPG.0000000000001402

22. Wu J, Wu S, Huo J, Ruan H, Xu X, Hao Z, et al. Systematic Characterization and Longitudinal Study Reveal Distinguishing Features of Human Milk Oligosaccharides in China. Curr Dev Nutr (2020) 4(8):nzaa113. doi: 10.1093/ cdn/nzaa113/5866471

23. Newburg DS, Ruiz-Palacios GM, Altaye M, Chaturvedi P, Meinzen-Derr J, Guerrero M de L, et al. Innate Protection Conferred by Fucosylated Oligosaccharides of Human Milk Against Diarrhea in Breastfed Infants. Glycobiology (2004) 14(3):253-63. doi: 10.1093/glycob/cwh020

24. Thurl S, Henker J, Siegel M, Tovar K, Sawatzki G. Detection of Four Human Milk Groups With Respect to Lewis Blood Group Dependent Oligosaccharides. Glycoconj J (1997) 501:299-306. doi: 10.3390/nu12082209

25. Saben JL, Abraham A, Bode L, Sims CR, Andres A. Third-Trimester Glucose Homeostasis in Healthy Women Is Differentially Associated With Human Milk Oligosaccharide Composition at 2 Months Postpartum by Secretor Phenotype. Nutrients (2020) 12(8):2209. doi: 10.3390/nu12082209

26. Gómez-Gallego C, Morales J, Monleón D, du Toit E, Kumar H, Linderborg K, et al. Human Breast Milk NMR Metabolomic Profile Across Specific Geographical Locations and Its Association With the Milk Microbiota. Nutrients (2018) 10(10):1355. doi: 10.3390/nu10101355

27. Marcobal A, Barboza M, Froehlich JW, Block DE, German JB, Lebrilla CB, et al. Consumption of Human Milk Oligosaccharides by Gut-Related Microbes. J Agric Food Chem (2010) 58(9):5334-40. doi: 10.1021/jf9044205

28. Rudloff S, Pohlentz G, Diekmann L, Egge H, Kunz C. Urinary Excretion of Lactose and Oligosaccharides in Preterm Infants Fed Human Milk or Infant Formula. Acta Paediatr (1996) 85(5):598-603. doi: 10.1111/j.1651-2227.1996.tb14095.x

29. Walsh C, Lane JA, van Sinderen D, Hickey RM. Human Milk Oligosaccharides: Shaping the Infant Gut Microbiota and Supporting Health. J Funct Foods (2020) 72:104074. doi: 10.1016/j.jff.2020.104074

30. Kiela PR, Ghishan FK. Physiology of Intestinal Absorption and Secretion. Best Pract Res Clin Gastroenterol (2016) 30(2):145-59. doi: 10.1016/ j.bpg.2016.02.007

31. Goehring KC, Kennedy AD, Prieto PA, Buck RH. Direct Evidence for the Presence of Human Milk Oligosaccharides in the Circulation of Breastfed Infants. PloS One (2014) 9(7):e101692. doi: 10.1371/journal.pone.0101692. Wiley AS, editor.

32. Jantscher-Krenn E, Aigner J, Reiter B, Köfeler H, Csapo B, Desoye G, et al. Evidence of Human Milk Oligosaccharides in Maternal Circulation Already During Pregnancy: A Pilot Study. Am J Physiol Metab (2019) 316(3):E34757. doi: 10.1152/ajpendo.00320.2018

33. Azad MB, Robertson B, Atakora F, Becker AB, Subbarao P, Moraes TJ, et al. Human Milk Oligosaccharide Concentrations are Associated With Multiple Fixed and Modifiable Maternal Characteristics, Environmental Factors, and Feeding Practices. J Nutr (2018) 148(11):1733-42. doi: 10.1093/jn/nxy175

34. Hirschmugl B, Brandl W, Csapo B, van Poppel M, Köfeler H, Desoye G, et al. Evidence of Human Milk Oligosaccharides in Cord Blood and Maternal-to-Fetal Transport Across the Placenta. Nutrients (2019) 11 (11):2640. doi: 10.3390/nu11112640

35. Salvo Romero E, Alonso Cotoner C, Pardo Camacho C, Casado Bedmar M, Vicario M. The Intestinal Barrier Function and its Involvement in Digestive Disease. Rev Esp Enferm Dig (2015) 107(11):686-96. doi: 10.17235/ reed.2015.3846/2015

36. Barker N, Ridgway RA, van Es JH, van de Wetering $M$, Begthel $H$, van den Born M, et al. Crypt Stem Cells as the Cells-of-Origin of Intestinal Cancer. Nature (2009) 457(7229):608-11. doi: 10.1038/nature07602

37. Angeloni S. Glycoprofiling With Micro-Arrays of Glycoconjugates and Lectins. Glycobiology (2004) 15(1):31-41. doi: 10.1093/glycob/cwh143
38. Kong C, Elderman M, Cheng L, Haan BJ, Nauta A, Vos P. Modulation of Intestinal Epithelial Glycocalyx Development by Human Milk Oligosaccharides and Non-Digestible Carbohydrates. Mol Nutr Food Res (2019) 63(17):1900303. doi: 10.1002/mnfr.201900303

39. Kuntz S, Rudloff S, Kunz C. Oligosaccharides From Human Milk Influence Growth-Related Characteristics of Intestinally Transformed and nonTransformed Intestinal Cells. Br J Nutr (2008) 99(3):462-71. doi: 10.1017/ S0007114507824068

40. Holscher HD, Davis SR, Tappenden KA. Human Milk Oligosaccharides Influence Maturation of Human Intestinal Caco-2Bbe and HT-29 Cell Lines. J Nutr (2014) 144(5):586-91. doi: 10.3945/jn.113.189704

41. Perdijk O, van Baarlen P, Fernandez-Gutierrez MM, van den Brink E, Schuren FHJ, Brugman S, et al. Sialyllactose and Galactooligosaccharides Promote Epithelial Barrier Functioning and Distinctly Modulate Microbiota Composition and Short Chain Fatty Acid Production In Vitro. Front Immunol (2019) 10:94/full. doi: 10.3389/fimmu.2019.00094/full

42. Bergstrom KSB, Xia L. Mucin-Type O-Glycans and Their Roles in Intestinal Homeostasis. Glycobiology (2013) 23(9):1026-37. doi: 10.1093/glycob/cwt045

43. Wu RY, Li B, Koike Y, Määttänen P, Miyake H, Cadete M, et al. Human Milk Oligosaccharides Increase Mucin Expression in Experimental Necrotizing Enterocolitis. Mol Nutr Food Res (2018) 12:1800658. doi: 10.1002/mnfr.201800658

44. Suligoj T, Vigsnæs LK, Abbeele PVd, Apostolou A, Karalis K, Savva GM, et al. Effects of Human Milk Oligosaccharides on the Adult Gut Microbiota and Barrier Function. Nutrients (2020) 12(9):2808. doi: 10.3390/nu12092808

45. Wells JM, Brummer RJ, Derrien M, MacDonald TT, Troost F, Cani PD, et al. Homeostasis of the Gut Barrier and Potential Biomarkers. Am J Physiol Liver Physiol (2017) 312(3):G171-93. doi: 10.1152/ajpgi.00048.2015

46. Chichlowski M, De Lartigue G, German JB, Raybould HE, Mills DA. Bifidobacteria Isolated From Infants and Cultured on Human Milk Oligosaccharides Affect Intestinal Epithelial Function. J Pediatr Gastroenterol Nutr (2012) 55(3):321-7. doi: 10.1097/MPG.0b013e31824fb899

47. Kim S, Kim G-H. Roles of Claudin-2, ZO-1 and Occludin in Leaky HK-2 Cells. PloS One (2017) 12(12):e0189221. doi: 10.1371/journal.pone.0189221. André F, editor.

48. Otani T, Nguyen TP, Tokuda S, Sugihara K, Sugawara T, Furuse K, et al. Claudins and JAM-A Coordinately Regulate Tight Junction Formation and Epithelial Polarity. J Cell Biol (2019) 218(10):3372-96. doi: 10.1083/jcb.201812157

49. ten Bruggencate SJ, Bovee-Oudenhoven IM, Feitsma AL, van Hoffen E, Schoterman MH. Functional Role and Mechanisms of Sialyllactose and Other Sialylated Milk Oligosaccharides. Nutr Rev (2014) 72(6):377-89. doi: $10.1111 /$ nure. 12106

50. Duncan PI, Raymond F, Fuerholz A, Sprenger N. Sialic Acid Utilisation and Synthesis in the Neonatal Rat Revisited. PloS One (2009) 4(12):e8241. doi: 10.1371/journal.pone.0008241. Tomé D, editor.

51. Zenhom M, Hyder A, de Vrese M, Heller KJ, Roeder T, Schrezenmeir J. Prebiotic Oligosaccharides Reduce Proinflammatory Cytokines in Intestinal Caco-2 Cells Via Activation of PPAR $\gamma$ and Peptidoglycan Recognition Protein 3. J Nutr (2011) 141(5):971-7. doi: 10.3945/jn.110.136176

52. Yu Z-T, Nanthakumar NN, Newburg DS. The Human Milk Oligosaccharide 2'-Fucosyllactose Quenches Campylobacter Jejuni-Induced Inflammation in Human Epithelial Cells Hep-2 and HT-29 and in Mouse Intestinal Mucosa. J Nutr (2016) 146(10):1980-90. doi: 10.3945/jn.116.230706

53. Zehra S, Khambati I, Vierhout M, Mian MF, Buck R, Forsythe P. Human Milk Oligosaccharides Attenuate Antigen-Antibody Complex Induced Chemokine Release From Human Intestinal Epithelial Cell Lines. J Food Sci (2018) 83(2):499-508. doi: 10.1111/1750-3841.14039

54. Pérez-Cano FJ. What Does Influence the Neonatal Microbiome? Nutrients (2020) 12(8):2472. doi: 10.3390/nu12082472

55. Rautava S, Luoto R, Salminen S, Isolauri E. Microbial Contact During Pregnancy, Intestinal Colonization and Human Disease. Nat Rev Gastroenterol Hepatol (2012) 9(10):565-76. doi: 10.1038/nrgastro. 2012.144

56. Palmer C, Bik EM, DiGiulio DB, Relman DA, Brown PO. Development of the Human Infant Intestinal Microbiota. PloS Biol (2007) 5(7):e177. doi: 10.1371/journal.pbio.0050177. Ruan Y, editor.

57. Yu Z-T, Chen C, Newburg DS. Utilization of Major Fucosylated and Sialylated Human Milk Oligosaccharides by Isolated Human Gut Microbes. Glycobiology (2013) 23(11):1281-92. doi: 10.1093/glycob/cwt065 
58. Wong $\mathrm{CB}$, Odamaki $\mathrm{T}$, Xiao J. Insights Into the Reason of HumanResidential Bifidobacteria (HRB) Being the Natural Inhabitants of the Human Gut and Their Potential Health-Promoting Benefits. FEMS Microbiol Rev (2020) 44(3):369-85. doi: 10.1093/femsre/fuaa010

59. Martín R, Bottacini F, Egan M, Chamignon C, Tondereau V, Moriez R, et al. The Infant-Derived Bifidobacterium Bifidum Strain CNCM I-4319 Strengthens Gut Functionality. Microorganisms (2020) 8(9):1313. doi: 10.3390/microorganisms8091313

60. Wexler AG, Goodman AL. An Insider's Perspective: Bacteroides as a Window Into the Microbiome. Nat Microbiol (2017) 2(5):17026. doi: 10.1038/nmicrobiol.2017.26

61. Heitkamp RA, Li P, Mende K, Demons ST, Tribble DR, Tyner SD. Association of Enterococcus Spp. With Severe Combat Extremity Injury, Intensive Care, and Polymicrobial Wound Infection. Surg Infect (Larchmt) (2018) 19(1):95-103. doi: 10.1089/sur.2017.157

62. Krzyściak W, Pluskwa KK, Jurczak A, Kościelniak D. The Pathogenicity of the Streptococcus Genus. Eur J Clin Microbiol Infect Dis (2013) 32(11):136176. doi: 10.1007/s10096-013-1914-9

63. Andreas NJ, Al-Khalidi A, Jaiteh M, Clarke E, Hyde MJ, Modi N, et al. Role of Human Milk Oligosaccharides in Group B Streptococcus Colonisation. Clin Transl Immunol (2016) 5(8):e99. doi: 10.1038/cti.2016.43

64. Lin AE, Autran CA, Szyszka A, Escajadillo T, Huang M, Godula K, et al. Human Milk Oligosaccharides Inhibit Growth of Group B Streptococcus. J Biol Chem (2017) 292(27):11243-9. doi: 10.1074/jbc.M117.789974

65. Salli K, Anglenius H, Hirvonen J, Hibberd AA, Ahonen I, Saarinen MT, et al. The Effect of 2'-Fucosyllactose on Simulated Infant Gut Microbiome and Metabolites; a Pilot Study in Comparison to GOS and Lactose. Sci Rep (2019) 9(1):13232. doi: 10.1038/s41598-019-49497-z

66. Barka EA, Vatsa P, Sanchez L, Gaveau-Vaillant N, Jacquard C, Klenk H-P, et al. Taxonomy, Physiology, and Natural Products of Actinobacteria. Microbiol Mol Biol Rev (2016) 80(1):1-43. doi: 10.1128/MMBR.00019-15

67. Rizzatti G, Lopetuso LR, Gibiino G, Binda C, Gasbarrini A. Proteobacteria: A Common Factor in Human Diseases. BioMed Res Int (2017) 2017:1-7. doi: $10.1155 / 2017 / 9351507$

68. Hoeflinger JL, Davis SR, Chow J, Miller MJ. In Vitro Impact of Human Milk Oligosaccharides on Enterobacteriaceae Growth. J Agric Food Chem (2015) 63(12):3295-302. doi: 10.1021/jf505721p

69. Kostopoulos I, Elzinga J, Ottman N, Klievink JT, Blijenberg B, Aalvink S, et al. Akkermansia Muciniphila Uses Human Milk Oligosaccharides to Thrive in the Early Life Conditions In Vitro. Sci Rep (2020) 10(1):14330. doi: 10.1038/s41598-020-71113-8

70. Cilieborg MS, Sangild PT, Jensen ML, Østergaard MV, Christensen L, Rasmussen SO, et al. $\alpha 1,2$-Fucosyllactose Does Not Improve Intestinal Function or Prevent Escherichia Coli F18 Diarrhea in Newborn Pigs. J Pediatr Gastroenterol Nutr (2017) 64(2):310-8. doi: 10.1097/MPG. 0000000000001276

71. Li M, Monaco MH, Wang M, Comstock SS, Kuhlenschmidt TB, Fahey GCJr., et al. Human Milk Oligosaccharides Shorten Rotavirus-Induced Diarrhea and Modulate Piglet Mucosal Immunity and Colonic Microbiota. ISME J (2014) 8(8):1609-20. doi: 10.1038/ismej.2014.10

72. Underwood MA, Gaerlan S, De Leoz MLA, Dimapasoc L, Kalanetra KM, Lemay DG, et al. Human Milk Oligosaccharides in Premature Infants: Absorption, Excretion, and Influence on the Intestinal Microbiota. Pediatr Res (2015) 78(6):670-7. doi: 10.1038/pr.2015.162

73. Korpela K, Salonen A, Hickman B, Kunz C, Sprenger N, Kukkonen K, et al. Fucosylated Oligosaccharides in Mother's Milk Alleviate the Effects of Caesarean Birth on Infant Gut Microbiota. Sci Rep (2018) 8(1):13757. doi: 10.1038/s41598-018-32037-6

74. Borewicz K, Gu F, Saccenti E, Arts ICW, Penders J, Thijs C, et al. Correlating Infant Fecal Microbiota Composition and Human Milk Oligosaccharide Consumption by Microbiota of 1-Month-Old Breastfed Infants. Mol Nutr Food Res (2019) 63(13):1801214. doi: 10.1002/mnfr.201801214

75. Park M, Kwon B, Ku S, Ji G. The Efficacy of Bifidobacterium Longum BORI and Lactobacillus Acidophilus AD031 Probiotic Treatment in Infants With Rotavirus Infection. Nutrients (2017) 9(8):887. doi: 10.3390/ nu9080887

76. Wexler HM. Bacteroides: The Good, the Bad, and the Nitty-Gritty. Clin Microbiol Rev (2007) 20(4):593-621. doi: 10.1128/CMR.00008-07
77. Wang M, Li M, Wu S, Lebrilla CB, Chapkin RS, Ivanov I, et al. Fecal Microbiota Composition of Breast-Fed Infants Is Correlated With Human Milk Oligosaccharides Consumed. J Pediatr Gastroenterol Nutr (2015) 60 (6):825-33. doi: 10.1097/MPG.0000000000000752

78. Lewis ZT, Totten SM, Smilowitz JT, Popovic M, Parker E, Lemay DG, et al. Maternal Fucosyltransferase 2 Status Affects the Gut Bifidobacterial Communities of Breastfed Infants. Microbiome (2015) 3(1):13. doi: $10.1186 / \mathrm{s} 40168-015-0071-\mathrm{z}$

79. Smith-Brown P, Morrison M, Krause L, Davies PSW. Mothers Secretor Status Affects Development of Childrens Microbiota Composition and Function: A Pilot Study. PloS One (2016) 11(9):e0161211. doi: 10.1371/ journal.pone.0161211. Weir TL, editor.

80. Tarr AJ, Galley JD, Fisher SE, Chichlowski M, Berg BM, Bailey MT. The Prebiotics 3'Sialyllactose and 6'Sialyllactose Diminish Stressor-Induced Anxiety-Like Behavior and Colonic Microbiota Alterations: Evidence for Effects on the Gut-Brain Axis. Brain Behav Immun (2015) 50:166-77. doi: 10.1016/j.bbi.2015.06.025

81. Ruiz-Moyano S, Totten SM, Garrido DA, Smilowitz JT, German JB, Lebrilla $\mathrm{CB}$, et al. Variation in Consumption of Human Milk Oligosaccharides by Infant Gut-Associated Strains of Bifidobacterium Breve. Appl Environ Microbiol (2013) 79(19):6040-9. doi: 10.1128/AEM.01843-13

82. Sela DA, Garrido D, Lerno L, Wu S, Tan K, Eom H-J, et al. Bifidobacterium Longum Subsp. Infantis ATCC $15697 \alpha$-Fucosidases Are Active on Fucosylated Human Milk Oligosaccharides. Appl Environ Microbiol (2012) 78(3):795-803. doi: 10.1128/AEM.06762-11

83. Kitaoka M. Bifidobacterial Enzymes Involved in the Metabolism of Human Milk Oligosaccharides. Adv Nutr (2012) 3(3):422S-9S. doi: 10.3945/ an. 111.001420

84. James K, O'Connell Motherway M, Penno C, O’Brien RL, van Sinderen D. Bifidobacterium Breve UCC2003 Employs Multiple Transcriptional Regulators to Control Metabolism of Particular Human Milk Oligosaccharides. Appl Environ Microbiol (2018) 84(9):e02774-17. doi: 10.1128/AEM.02774-17. Cann I, editor.

85. Glanz VY, Myasoedova VA, Grechko AV, Orekhov AN. Sialidase Activity in Human Pathologies. Eur J Pharmacol (2019) 842:345-50. doi: 10.1016/ j.ejphar.2018.11.014

86. de la Cuesta-Zuluaga J, Mueller N, Álvarez-Quintero R, Velásquez-Mejía E, Sierra J, Corrales-Agudelo V, et al. Higher Fecal Short-Chain Fatty Acid Levels are Associated With Gut Microbiome Dysbiosis, Obesity, Hypertension and Cardiometabolic Disease Risk Factors. Nutrients (2018) 11(1):51. doi: 10.3390/nu11010051

87. Kelly D, Coutts AGP. Early Nutrition and the Development of Immune Function in the Neonate. Proc Nutr Soc (2000) 59(2):177-85. doi: 10.1017/ S0029665100000197

88. Kulinich A, Liu L. Human Milk Oligosaccharides: The Role in the FineTuning of Innate Immune Responses. Carbohydr Res (2016) 432:62-70. doi: 10.1016/j.carres.2016.07.009

89. Plaza-Díaz J, Fontana L, Gil A. Human Milk Oligosaccharides and Immune System Development. Nutrients (2018) 10(8):1038. doi: 10.3390/nu10081038

90. Round JL, Mazmanian SK. Inducible Foxp3+ Regulatory T-cell Development by a Commensal Bacterium of the Intestinal Microbiota. Proc Natl Acad Sci (2010) 107(27):12204-9. doi: 10.1073/pnas.0909122107

91. Pucino V, Bombardieri M, Pitzalis C, Mauro C. Lactate at the Crossroads of Metabolism, Inflammation, and Autoimmunity. Eur J Immunol (2017) 47 (1):14-21. doi: 10.1002/eji.201646477

92. Gonçalves P, Araújo JR, Di Santo JP. A Cross-Talk Between MicrobiotaDerived Short-Chain Fatty Acids and the Host Mucosal Immune System Regulates Intestinal Homeostasis and Inflammatory Bowel Disease. Inflamm Bowel Dis (2018) 24(3):558-72. doi: 10.1093/ibd/izx029

93. Hirabayashi J. Oligosaccharide Specificity of Galectins: A Search by Frontal Affinity Chromatography. Biochim Biophys Acta - Gen Subj (2002) 1572(23):232-54. doi: 10.1016/S0304-4165(02)00311-2

94. Rapoport EM, Kurmyshkina OV, Bovin NV. Mammalian Galectins: Structure, Carbohydrate Specificity, and Functions. Biochem (2008) 73 (4):393-405. doi: 10.1134/S0006297908040032

95. O'Reilly MK, Paulson JC. Siglecs as Targets for Therapy in Immune-CellMediated Disease. Trends Pharmacol Sci (2009) 30(5):240-8. doi: 10.1016/ j.tips.2009.02.005 
96. Bode L, Kunz C, Muhly-Reinholz M, Mayer K, Seeger W, Rudloff S. Inhibition of Monocyte, Lymphocyte, and Neutrophil Adhesion to Endothelial Cells by Human Milk Oligosaccharides. Thromb Haemost (2004) 92(12):1402-10. doi: 10.1160/TH04-01-0055

97. Schumacher G, Bendas G, Stahl B, Beermann C. Human Milk Oligosaccharides Affect P-selectin Binding Capacities: In Vitro Investigation. Nutrition (2006) 22(6):620-7. doi: 10.1016/j.nut.2005.12.009

98. Bode L, Rudloff S, Kunz C, Strobel S, Klein N. Human Milk Oligosaccharides Reduce Platelet-Neutrophil Complex Formation Leading to a Decrease in Neutrophil $\beta 2$ Integrin Expression. J Leukoc Biol (2004) 76(4):820-6. doi: 10.1189/jlb.0304198

99. Newburg DS, Tanritanir AC, Chakrabarti S. Lactodifucotetraose, a Human Milk Oligosaccharide, Attenuates Platelet Function and Inflammatory Cytokine Release. J Thromb Thrombolysis (2016) 42(1):46-55. doi: 10.1007/s11239-015-1331-2

100. Noll AJ, Yu Y, Lasanajak Y, Duska-McEwen G, Buck RH, Smith DF, et al. Human DC-SIGN Binds Specific Human Milk Glycans. Biochem J (2016) 473(10):1343-53. doi: 10.1042/BCJ20160046

101. Huang F-L, Liao E-C, Yu S-J. House Dust Mite Allergy: Its Innate Immune Response and Immunotherapy. Immunobiology (2018) 223(3):300-2. doi: 10.1016/j.imbio.2017.10.035

102. Lane JA, O'Callaghan J, Carrington SD, Hickey RM. Transcriptional Response of HT-29 Intestinal Epithelial Cells to Human and Bovine Milk Oligosaccharides. Br J Nutr (2013) 110(12):2127-37. doi: 10.1017/ S0007114513001591

103. He Y, Lawlor NT, Newburg DS. Human Milk Components Modulate TollLike Receptor-Mediated Inflammation. Adv Nutr (2016) 7(1):102-11. doi: 10.3945/an.115.010090

104. Thomas PG, Carter MR, Atochina O, Da'Dara AA, Piskorska D, McGuire E, et al. Maturation of Dendritic Cell 2 Phenotype by a Helminth Glycan Uses a Toll-Like Receptor 4-Dependent Mechanism. J Immunol (2003) 171 (11):5837-41. doi: 10.4049/jimmunol.171.11.5837

105. Atochina O, Harn D. LNFPIII/Lex-Stimulated Macrophages Activate Natural Killer Cells Via CD40-CD40L Interaction. Clin Diagn Lab Immunol (2005) 12(9):1041-9. doi: 10.1128/CDLI.12.9.1041-1049.2005

106. Xiao L, Worp WR, Stassen R, Maastrigt C, Kettelarij N, Stahl B, et al. Human Milk Oligosaccharides Promote Immune Tolerance Via Direct Interactions With Human Dendritic Cells. Eur J Immunol (2019) 49(7):1001-14. doi: 10.1002/eji.201847971

107. Ayechu-Muruzabal V, Overbeek SA, Kostadinova AI, Stahl B, Garssen J, van't Land B, et al. Exposure of Intestinal Epithelial Cells to 2'-Fucosyllactose and CpG Enhances Galectin Release and Instructs Dendritic Cells to Drive Th1 and Regulatory-Type Immune Development. Biomolecules (2020) 10 (5):784. doi: 10.3390/biom10050784

108. Kurakevich E, Hennet T, Hausmann M, Rogler G, Borsig L. Milk Oligosaccharide Sialyl (2,3)Lactose Activates Intestinal CD11c+ Cells Through TLR4. Proc Natl Acad Sci (2013) 110(43):17444-9. doi: 10.1073/pnas.1306322110

109. Perdijk O, van Neerven RJJ, van den Brink E, Savelkoul HFJ, Brugman S. The Oligosaccharides 6'-Sialyllactose, 2'-Fucosyllactose or Galactooligosaccharides do Not Directly Modulate Human Dendritic Cell Differentiation or Maturation. PloS One (2018) 13(7):e0200356. doi: 10.1371/ journal.pone.0200356. Haziot A, editor.

110. He-Yang J, Zhang W, Liu J, Xue P, Zhou X. Human Breast Milk Oligosaccharides Attenuate Necrotizing Enterocolitis in Rats by Suppressing Mast Cell Accumulation, DPPI Activity and TLR4 Expression in Ileum Tissue, and Regulating Mitochondrial Damage of Caco-2 Cells. Int Immunopharmacol (2020) 88:106881. doi: 10.1016/j.intimp.2020.106881

111. He Y, Liu S, Leone S, Newburg DS. Human Colostrum Oligosaccharides Modulate Major Immunologic Pathways of Immature Human Intestine. Mucosal Immunol (2014) 7(6):1326-39. doi: 10.1038/mi.2014.20

112. Eiwegger T, Stahl B, Haidl P, Schmitt J, Boehm G, Dehlink E, et al. Prebiotic Oligosaccharides: In Vitro Evidence for Gastrointestinal Epithelial Transfer and Immunomodulatory Properties. Pediatr Allergy Immunol (2010) 21 (8):1179-88. doi: 10.1111/j.1399-3038.2010.01062.x

113. Velupillai P, Harn DA. Oligosaccharide-Specific Induction of Interleukin 10 Production by B220+ Cells From Schistosome-Infected Mice: A Mechanism for Regulation of CD4+ T-Cell Subsets. Proc Natl Acad Sci (1994) 91(1):1822. doi: $10.1073 /$ pnas.91.1.18
114. Xiao L, Leusink-Muis T, Kettelarij N, van Ark I, Blijenberg B, Hesen NA, et al. Human Milk Oligosaccharide 2'-Fucosyllactose Improves Innate and Adaptive Immunity in an Influenza-Specific Murine Vaccination Model. Front Immunol (2018) 9:452/full. doi: 10.3389/fimmu.2018.00452/full

115. Eiwegger T, Stahl B, Schmitt J, Boehm G, Gerstmayr M, Pichler J, et al. Human Milk-Derived Oligosaccharides and Plant-Derived Oligosaccharides Stimulate Cytokine Production of Cord Blood T-Cells In Vitro. Pediatr Res (2004) 56(4):536-40. doi: 10.1203/01.PDR.0000139411.35619.B4

116. Sotgiu S, Arru G, Fois ML, Sanna A, Musumeci M, Rosati G, et al. Immunomodulation of Fucosyl-Lactose and Lacto-N-Fucopentaose on Mononuclear Cells From Multiple Sclerosis and Healthy Subjects. Int J BioMed Sci (2006) 2(2):114-20.

117. Goehring KC, Marriage BJ, Oliver JS, Wilder JA, Barrett EG, Buck RH. Similar to Those Who Are Breastfed, Infants Fed a Formula Containing 2'Fucosyllactose Have Lower Inflammatory Cytokines in a Randomized Controlled Trial. J Nutr (2016) 146(12):2559-66. doi: 10.3945/jn.116.236919

118. Wiciński M, Sawicka E, Gębalski J, Kubiak K, Malinowski B. Human Milk Oligosaccharides: Health Benefits, Potential Applications in Infant Formulas, and Pharmacology. Nutrients (2020) 12(1):266. doi: 10.3390/ nu12010266

119. Grummer-Strawn LM, Mei Z. Does Breastfeeding Protect Against Pediatric Overweight? Analysis of Longitudinal Data From the Centers for Disease Control and Prevention Pediatric Nutrition Surveillance System. Pediatrics (2004) 113(2):e81-6. doi: 10.1542/peds.113.2.e81

120. Fleming SA, Mudd AT, Hauser J, Yan J, Metairon S, Steiner P, et al. Dietary Oligofructose Alone or in Combination With 2'-Fucosyllactose Differentially Improves Recognition Memory and Hippocampal mRNA Expression. Nutrients (2020) 12(7):2131. doi: 10.3390/nu12072131

121. Yang B, Chuang H, Yang KD. Sialylated Glycans as Receptor and Inhibitor of Enterovirus 71 Infection to DLD-1 Intestinal Cells. Virol J (2009) 6(1):141. doi: $10.1186 / 1743-422 \mathrm{X}-6-141$

122. Andersson B, Porras O, Hanson LA, Lagergard T, Svanborg-Eden C. Inhibition of Attachment of Streptococcus Pneumoniae and Haemophilus Influenzae by Human Milk and Receptor Oligosaccharides. J Infect Dis (1986) 153(2):232-7. doi: 10.1093/infdis/153.2.232

123. Ackerman DL, Doster RS, Weitkamp J-H, Aronoff DM, Gaddy JA, Townsend SD. Human Milk Oligosaccharides Exhibit Antimicrobial and Antibiofilm Properties Against Group B Streptococcus. ACS Infect Dis (2017) 3(8):595-605. doi: 10.1021/acsinfecdis.7b00064

124. Weichert S, Koromyslova A, Singh BK, Hansman S, Jennewein S, Schroten $\mathrm{H}$, et al. Structural Basis for Norovirus Inhibition by Human Milk Oligosaccharides. J Virol (2016) 90(9):4843-8. López S, editor. doi: 10.1128/JVI.03223-15

125. Lin AE, Autran CA, Espanola SD, Bode L, Nizet V. Human Milk Oligosaccharides Protect Bladder Epithelial Cells Against Uropathogenic Escherichia Coli Invasion and Cytotoxicity. J Infect Dis (2014) 209(3):38998. doi: 10.1093/infdis/jit464

126. Harris JE, Pinckard KM, Wright KR, Baer LA, Arts PJ, Abay E, et al. Exercise-Induced $3^{\prime}$-Sialyllactose in Breast Milk is a Critical Mediator to Improve Metabolic Health and Cardiac Function in Mouse Offspring. Nat Metab (2020) 2(8):678-87. doi: 10.1038/s42255-020-0223-8

127. Simon D. Recent Advances in Clinical Allergy and Immunology 2019. Int Arch Allergy Immunol (2019) 180(4):291-305. doi: 10.1159/000504364

128. Shu S-A, Yuen AWT, Woo E, Chu K-H, Kwan H-S, Yang G-X, et al. Microbiota and Food Allergy. Clin Rev Allergy Immunol (2019) 57(1):83-97. doi: 10.1007/s12016-018-8723-y

129. Hellings PW, Steelant B. Epithelial Barriers in Allergy and Asthma. J Allergy Clin Immunol (2020) 145(6):1499-509. doi: 10.1016/j.jaci.2020.04.010

130. Castillo-Courtade L, Han S, Lee S, Mian FM, Buck R, Forsythe P. Attenuation of Food Allergy Symptoms Following Treatment With Human Milk Oligosaccharides in a Mouse Model. Allergy (2015) 70 (9):1091-102. doi: 10.1111/all.12650

131. Liu T, Chen P, Munir M, Liu L, Li C, Li A, et al. HMOs Modulate Immunoregulation and Gut Microbiota in a $\beta$-Lactoglobulin-Induced Allergic Mice Model. J Funct Foods (2020) 70:103993. doi: 10.1016/ j.jff.2020.103993

132. Sprenger N, Odenwald H, Kukkonen AK, Kuitunen M, Savilahti E, Kunz C. FUT2-Dependent Breast Milk Oligosaccharides and Allergy at 2 and 5 Years 
of Age in Infants With High Hereditary Allergy Risk. Eur J Nutr (2017) 56 (3):1293-301. doi: 10.1007/s00394-016-1180-6

133. Brosseau C, Selle A, Palmer DJ, Prescott SL, Barbarot S, Bodinier M. Prebiotics: Mechanisms and Preventive Effects in Allergy. Nutrients (2019) 11(8):1841. doi: 10.3390/nu11081841

134. Venter C, Brown KR, Maslin K, Palmer DJ. Maternal Dietary Intake in Pregnancy and Lactation and Allergic Disease Outcomes in Offspring. Pediatr Allergy Immunol (2017) 28(2):135-43. doi: 10.1111/pai.12682

135. Pretorius R, Prescott SL, Palmer DJ. Taking a Prebiotic Approach to Early Immunomodulation for Allergy Prevention. Expert Rev Clin Immunol (2018) 14(1):43-51. doi: 10.1080/1744666X.2018.1411191

136. Cabridain C, Aubert H, Kaeffer B, Badon V, Boivin M, Dochez V, et al. Effectiveness of an Antenatal Maternal Supplementation With Prebiotics for Preventing Atopic Dermatitis in High-Risk Children (the PREGRALL
Study): Protocol for a Randomised Controlled Trial. BMJ Open (2019) 9 (4):e024974. doi: 10.1136/bmjopen-2018-024974

Conflict of Interest: The authors declare that the research was conducted in the absence of any commercial or financial relationships that could be construed as a potential conflict of interest.

Copyright (๑) 2021 Rousseaux, Brosseau, Le Gall, Piloquet, Barbarot and Bodinier. This is an open-access article distributed under the terms of the Creative Commons Attribution License (CC BY). The use, distribution or reproduction in other forums is permitted, provided the original author(s) and the copyright owner(s) are credited and that the original publication in this journal is cited, in accordance with accepted academic practice. No use, distribution or reproduction is permitted which does not comply with these terms. 